\title{
Characterisation of the spatial variability of material properties of Gilsocarbon and NBG-18 using random fields
}

DOI:

10.1016/j.jnucmat.2018.09.008

\section{Document Version}

Accepted author manuscript

Link to publication record in Manchester Research Explorer

\section{Citation for published version (APA):}

Arregui-Mena, J., Edmondson, P. D., Margetts, L., Griffiths, D. V., Windes, W. E., Carroll, M., \& Mummery, P. (2018). Characterisation of the spatial variability of material properties of Gilsocarbon and NBG-18 using random fields. Journal of Nuclear Materials. https://doi.org/10.1016/j.jnucmat.2018.09.008

\section{Published in:}

Journal of Nuclear Materials

\section{Citing this paper}

Please note that where the full-text provided on Manchester Research Explorer is the Author Accepted Manuscript or Proof version this may differ from the final Published version. If citing, it is advised that you check and use the publisher's definitive version.

\section{General rights}

Copyright and moral rights for the publications made accessible in the Research Explorer are retained by the authors and/or other copyright owners and it is a condition of accessing publications that users recognise and abide by the legal requirements associated with these rights.

\section{Takedown policy}

If you believe that this document breaches copyright please refer to the University of Manchester's Takedown Procedures [http://man.ac.uk/04Y6Bo] or contact uml.scholarlycommunications@manchester.ac.uk providing relevant details, so we can investigate your claim.

\section{OPEN ACCESS}




\title{
Characterisation of the spatial variability of material properties of Gilsocarbon and NBG-18 using random fields 论
}

\author{
${ }^{\mathrm{a}}$ José David Arregui-Mena ${ }^{*}{ }^{\mathrm{a}}$ Philip D. Edmondson, ${ }^{\mathrm{b}}$ Lee Margetts, ${ }^{\mathrm{c}}$ D. V. Griffiths, ${ }^{\mathrm{d}}$ William \\ E. Windes, ${ }^{\mathrm{d}}$ Mark Carroll, ${ }^{\mathrm{b}}$ Paul M Mummery \\ a Oak Ridge National Laboratory, Oak Ridge, TN 37831, USA \\ ${ }^{\mathrm{b}}$ University of Manchester, Oxford Road Manchester, M13 9PL \\ ${ }^{c}$ Colorado School of Mines, 1500 Illinois St., Golden, CO, 80401, USA \\ ${ }^{\mathrm{d}}$ Idaho National Laboratory, Idaho Falls, ID, 83415, USA
}

\begin{abstract}
Graphite is a candidate material for Generation IV concepts and is used as a moderator in Advanced Gas-cooled Reactors (AGR) in the UK. Spatial material variability is present within billets causing different material property values between different components. Variations in material properties and irradiation effects can produce stress concentrations and diverse mechanical responses in a nuclear reactor graphite core. In order to characterise the material variability, geostatistical techniques called variography and random field theory were adapted for studying the density and Young's modulus of a billet of Gilsocarbon and NBG-18 graphite grades. Variography is a technique for estimating the distance over which material property values have significant spatial correlation, known as the scale of fluctuation or spatial correlation length. The paper uses random field theory to create models that mimic the original spatial and statistical distributions of the original data set. This study found different values of correlation length for density and Young's modulus around the edges of a Gilsocarbon billet, while in the case of NBG-18, similar correlation lengths where found across the billet. Examples of several random fields are given to reproduce the spatial patterns and values found in the original data.
\end{abstract}

Corresponding author: * José David Arregui-Mena (arreguimenjd@ ornl.gov - (1)865-316-8158) is This manuscript has been authored by UT-Battelle, LLC, under contract DE-AC05-00OR22725 with the US Department of Energy (DOE). The US government retains and the publisher, by accepting the article for publication, acknowledges that the US government retains a nonexclusive, paid-up, irrevocable, worldwide license to publish or reproduce the published form of this manuscript, or allow others to do so, for US government purposes. DOE will provide public access to these results of federally sponsored research in accordance with the DOE Public Access Plan (http://energy.gov/downloads/doe-public-access-plan). 


\section{Introduction}

Graphite components are deployed in multiple present-day nuclear power stations including the Advanced Gas-cooled Reactors (AGR) in the UK and will be part of Generation IV designs such as the Very High Temperature Reactor (VHTR) and some Molten Salt Reactors (MSR) concepts. The graphite core of these reactors designs serve as a moderator of fast neutrons, repository for fuel, and to provide structural support [1]. The reactor environment promotes several ageing mechanisms in the graphite components that lead to material property and dimensional changes. Examples of these mechanisms are the irradiation dimensional changes, irradiation creep, thermal strains and oxidation. The combination of these ageing and degradation mechanisms may lead to the distortion and internal stresses of individual components that in time can result in the formation and propagation of cracks. When enough graphite components crack or deform, the geometry of the core may interrupt the normal operations of a nuclear reactor, such as refuelling operations and the cooling thermodynamics of the graphite core. Thousands of graphitic bricks form the reactor core, the mechanical response of each of these components is highly dependent on the fluence, temperature profile, coolant and mechanical properties of the specific graphite grade. A certain degree of mechanical property variability is expected to be found inside and in-between billets. This variability is normally not accounted by the assessment and inspections on the graphite core.

Part of the routine assessments and predictions of the lifetime of graphite components include Finite Element Method (FEM) simulations. Assessments based on FEM models require an extensive database of the unirradiated and irradiated response of graphite. Some examples of FEM analysis for AGR components can be found in literature [2-4]. In general, these models include the effects of thermal expansion, irradiation-induced dimensional changes, irradiation creep and other ageing mechanisms that may alter the constitution of a graphite component. The structural integrity studies of graphite components are usually supported by stress analysis and other calculations that estimate the failure rate and lifetime of the components. In addition to stress analysis, several fracture mechanics techniques have been implemented to analyse the crack evolution in nuclear graphite components [5-9]. Traditionally FEM and continuum damage techniques use the mean values of material properties to perform their analyses. Unfortunately, by only using the mean value of the material properties all the spatial and statistical information 
such as standard deviation and probability distribution are lost. A previous study that includes spatial material variability into FEM has demonstrated that heterogeneity of material properties in AGR reactors can lead to stress concentrations [10]. Moreover, recent studies [11-13] have included or analysed the heterogeneity of material properties as they relate to the mechanical properties of graphite. Moreover, different characterization techniques such as optical microscopy [14], x-ray tomography [15] and FIB-SEM tomography have demonstrated the complex microstructure of graphite [16].

Quantifying the degree of heterogeneity of graphite components is essential to predict possible differences on the failure rate of graphite components. Inconsistencies in material properties may lead to the generation of stress concentrations - this effect can be produced by the combination of a temperature gradient and a significant heterogeneity of material properties in the graphite bricks [17]. A similar effect can be expected to be produced by the combination of irradiationinduced dimensional change and material property variation within a single graphite component.

The objectives of this research are to characterise the material's spatial variability through geostatistical techniques and reproduce the spatial fluctuations of two grades of nuclear graphite through mathematical models called random fields. The characterisation of spatial fluctuations only requires additional calculations that provide a new insight on the variations of materials properties within a billet. Alternatively, random field realisations reproduce models of the spatial fluctuations found in graphite allowing the modeller and designers to simulate different scenarios. This research focuses on the density and dynamic Young's modulus parameters of Gilsocarbon and NBG-18, although other material properties of interest can also be studied using this methodology.

\subsection{Background}

Several studies have shown the presence of heterogeneity of material properties in graphite components. These studies have been carried out for Gilsocarbon, the moderator of AGRs [1820], H-451 used at Peach Bottom and Ft. St. Vrain reactors (USA) [21, 22], IG-110 [23] and NBG-18 [24] a modern graphite grade proposed for future VHTRs.

Gilsocarbon is a medium grain graphite composed of spherical onion-shaped filler particles that are moulded during the manufacturing process [25]. The combination of moulding and spherical 
particles in Gilsocarbon result in an isotropic or semi-isotropic mechanical behaviour. The name of Gilsocarbon grade was given to the family of graphite grades designed for the AGRs in the UK. All these grades differ from each other as they were manufactured by two different companies, Anglo Great Lakes Corporation Limited (AGL) and Union Carbide. Although all of these grades were manufactured in similar conditions, they have slightly different grain sizes and microstructure. Several studies were conducted on the possible variations of properties among these graphite grades and within single billets. The first published measurements on the spatial variability of the physical and mechanical properties in Gilsocarbon within a single billet were conducted by Preston $[19,20]$. Approximately half of a billet was sectioned to measure several types of physical and mechanical properties. These measurements include density, electrical resistivity, coefficient of thermal expansion, four-point bending strength, compressive strength, Young's modulus, tensile strength, thermal conductivity, open pore volume, closed pore volume and Poisson's ratio. These studies confirmed the spatial variability of material's physical and mechanical properties. However, the data by Preston are not ideal for calibrating a random field for the purposes of this study because of the lack of a public database of material properties. Therefore, another source of density and dynamic Young's modulus was used for the calculations of this study [26].

The second material examined here, NBG-18, was a candidate grade for a component of the Pebble Bed Modular Reactor (PBMR) and is also being proposed as a material for other types of VHTRs. This graphite grade is manufactured from pitch coke and vibrationally moulded with a medium grain size (about $1.6 \mathrm{~mm}$ ) [27, 28]. An extensive qualification research program was developed for this grade at Idaho National Laboratory. Part of this program focused on the characterisation of a single unirradiated billet of NBG-18 and is also a guideline for future studies for other grades of graphite. For this research a billet of this grade was sectioned into 770 specimens that were used to measure the density, compressive strength, tensile strength, Young's modulus, shear modulus and other mechanical properties. The mechanical performance of this graphite grade under irradiation is also currently being investigated under the Advanced Graphite Creep programs (AGC) AGC-1 [28] and AGC-2 [29]. 


\section{Materials}

\subsection{Gilsocarbon data}

The density and Young's modulus variability of material properties were obtained by sectioning a billet of Gilsocarbon provided by EDF Energy Nuclear Generation Ltd. This billet was manufactured by Union Carbide for the Torness/Heysham II reactors (heat 4904; serial number 07V3632). The samples were sectioned from a billet with dimensions of $930 \mathrm{~mm}$ in height and $470 \mathrm{~mm}$ in diameter (Figure 1a). Samples were extracted close to the edge of the brick to facilitate the traceability and cutting of the samples. The geometry and dimensions of an AGR reactor can vary depending on the nuclear power station. A typical channel brick diameter size is approximately $460 \mathrm{~mm}$ and has a height between 850-900 mm. Figure 1b shows a channel brick of Hartlepool/Heysham AGR bricks.

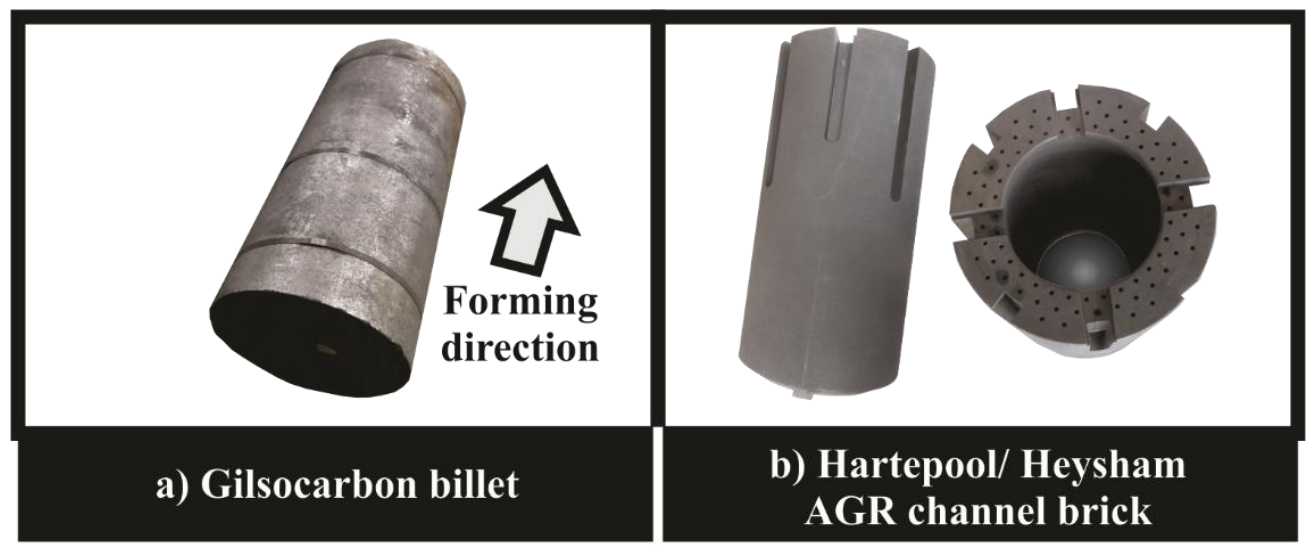

Figure 1. Gilsocarbon components: a) Tested Gilsocarbon billet, b) Example of a Hartlepool/Heysham AGR channel brick.

The billet was cut into 508 cubic samples to obtain the density and dynamic Young's modulus of the samples. ASTM standards were followed to conduct the measurements: ASTM Standard C559-90 [30] for density and ASTM standard C769-09 [31] for dynamic Young's modulus. (The complete data set can be found in reference [32].) A subset of 328 samples were used for the calculations of this research and the locations of these samples are shown in Figure 2. The regions where the samples were obtained from are labelled as spines. The position and values of density and dynamic Young's modulus for the spine sections can be found in Figure 3 and Figure 
4, respectively. For a more detailed description of the acquisition and data information the reader is referred to Reference [32].

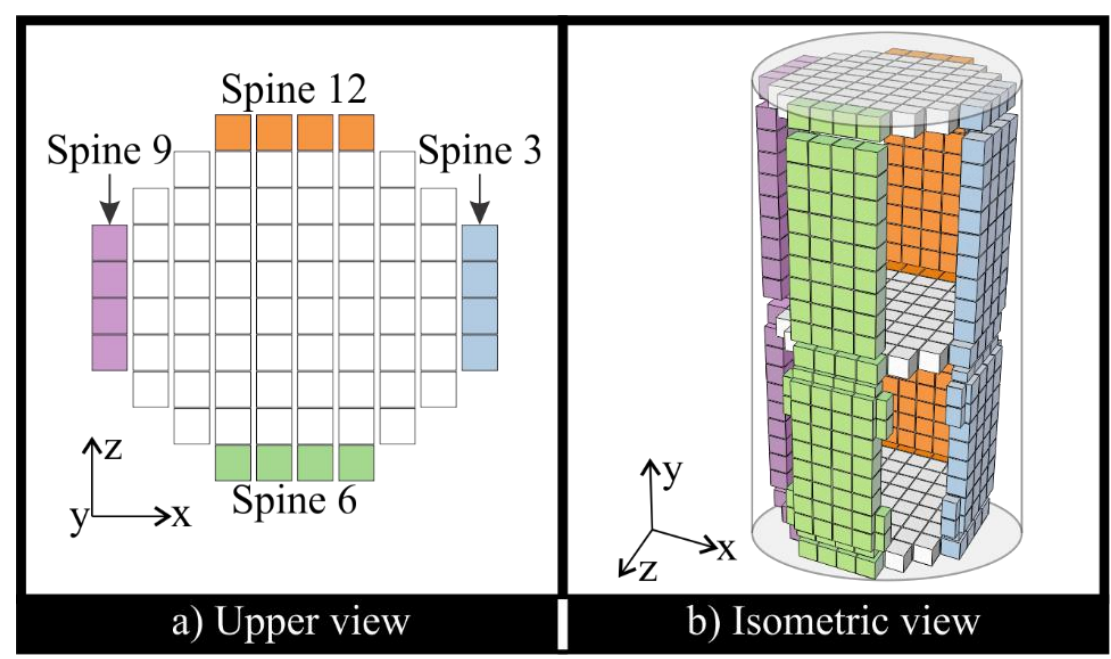

Figure 2. Cutting plan for the Gilsocarbon graphite billet: a) Upper view, b) Isometric view.

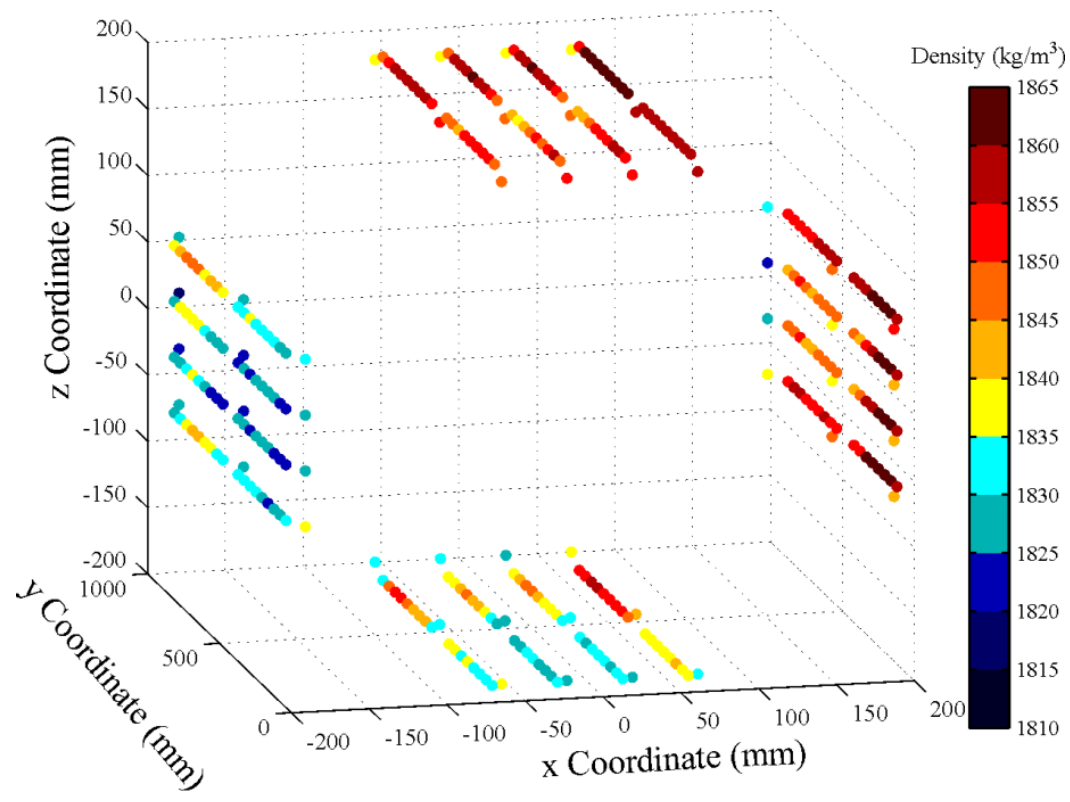

Figure 3. Density values for Gilsocarbon specimens.

The summary of the density and Young's modulus values for Gilsocarbon are divided in Table 1 and Table 2. These statistical values were used as input values for the random field generator described in the results sections. 


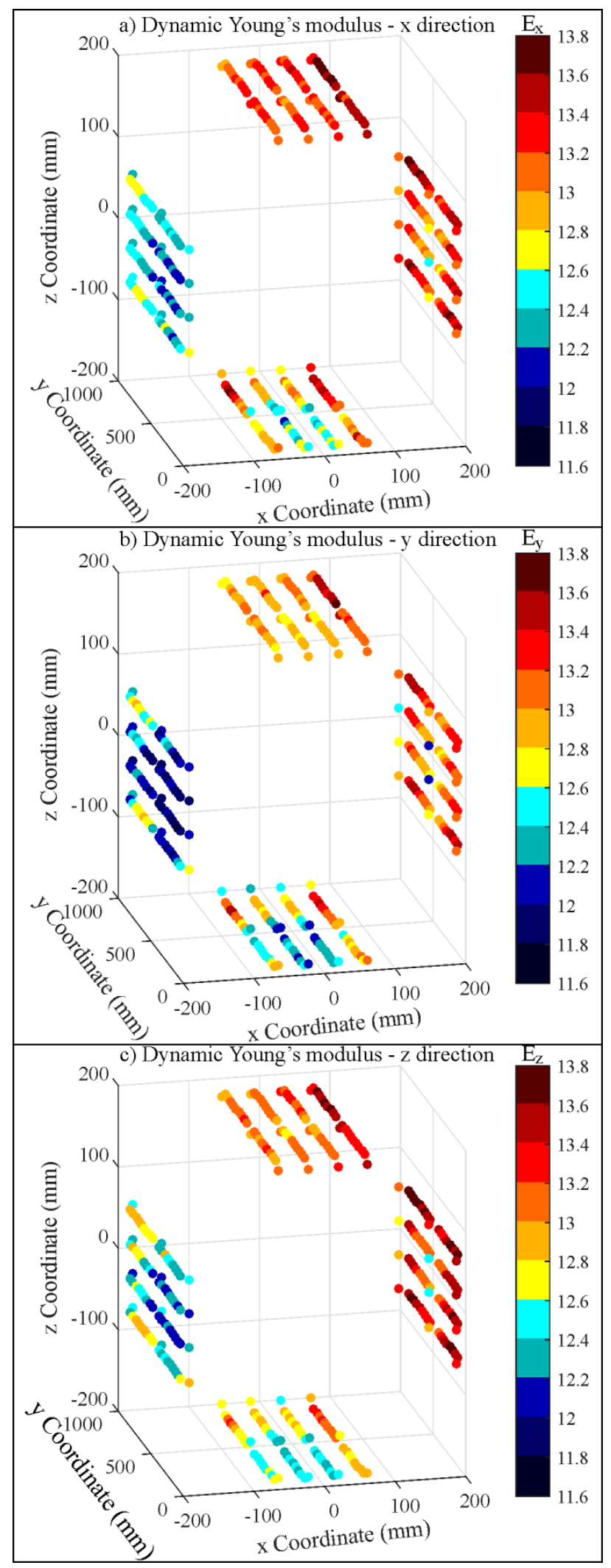

Figure 4. Dynamic Young's modulus values for Gilsocarbon specimens. 
Table 1. Mean and standard deviation for density of Gilsocarbon data.

\begin{tabular}{|c|c|c|c|}
\hline Section & $\begin{array}{l}\text { Density mean } \\
\text { value }\left(\mathrm{kg} / \mathrm{m}^{3}\right)\end{array}$ & $\begin{array}{l}\text { Density standard } \\
\text { deviation }\left(\mathrm{kg} / \mathrm{m}^{3}\right)\end{array}$ & $\begin{array}{c}\text { Number of } \\
\text { samples }\end{array}$ \\
\hline All spines data & 1843.34 & 12.19 & 328 \\
\hline Spine 3 & 1830.53 & 6.48 & 80 \\
\hline Spine 6 & 1838.02 & 8.17 & 80 \\
\hline Spine 9 & 1853.07 & 6.73 & 84 \\
\hline Spine 12 & 1851.80 & 8.66 & 84 \\
\hline
\end{tabular}

Table 2. Mean and standard deviation for Young's modulus of Gilsocarbon data.

\begin{tabular}{|c|c|c|c|c|c|c|c|}
\hline Section & $\begin{array}{c}\text { YM mean } \\
\text { X direction } \\
(\mathbf{G P a})\end{array}$ & $\begin{array}{c}\text { YM } \\
\text { standard } \\
\text { deviation X } \\
\text { direction } \\
\text { (GPa) }\end{array}$ & $\begin{array}{c}\text { YM mean } \\
\text { Y direction } \\
(\mathbf{G P a})\end{array}$ & $\begin{array}{c}\text { YM } \\
\text { standard } \\
\text { deviation Y } \\
\text { direction } \\
\text { (GPa) }\end{array}$ & $\begin{array}{c}\text { YM mean } \\
\text { Z direction } \\
(\mathbf{G P a})\end{array}$ & $\begin{array}{c}\text { YM } \\
\text { standard } \\
\text { deviation Z } \\
\text { direction } \\
\text { (GPa) }\end{array}$ & $\begin{array}{c}\text { Number of } \\
\text { samples }\end{array}$ \\
\hline $\begin{array}{c}\text { All spines } \\
\text { data }\end{array}$ & 12.945 & 0.445 & 12.742 & 0.468 & 12.911 & 0.439 & 328 \\
\hline Spine 3 & 12.381 & 0.182 & 12.192 & 0.292 & 12.446 & 0.254 & 80 \\
\hline Spine 6 & 12.869 & 0.349 & 12.669 & 0.371 & 12.704 & 0.282 & 80 \\
\hline Spine 9 & 13.290 & 0.186 & 13.005 & 0.224 & 13.157 & 0.207 & 84 \\
\hline Spine 12 & 13.244 & 0.247 & 13.108 & 0.285 & 13.334 & 0.275 & 84 \\
\hline
\end{tabular}

YM - Young's modulus

\subsection{NBG-18 data}

The measurements for the NBG-18 data were obtained from a commercial block of graphite labelled NBG-18 635-14. The original dimensions of the tested billet were $1828.8 \mathrm{~mm} \times 609.6$ $\mathrm{mm} \times 508 \mathrm{~mm}$. This block was sectioned into smaller samples to produce samples suitable for density, dynamic Young's modulus, Coefficient of Thermal Expansion (CTE) and strength tests. 
Example prismatic block designs for the VHTR is shown in Figure 5a (fuel block) and Figure 5b (reflector block). The approximate dimensions of this design of bricks are $787.4 \mathrm{~mm}$ tall and $406.4 \mathrm{~mm}$ diameter. The data points locations and values of density and Young's modulus for NBG-18 are represented in the data maps of Figure 6 and Figure 7. A more in-depth description of the measurements and data can be found in Reference [24]. Density and dynamic Young's modulus measurements were obtained following the ASTM C559 [30] and ASTM C769 [31], respectively.

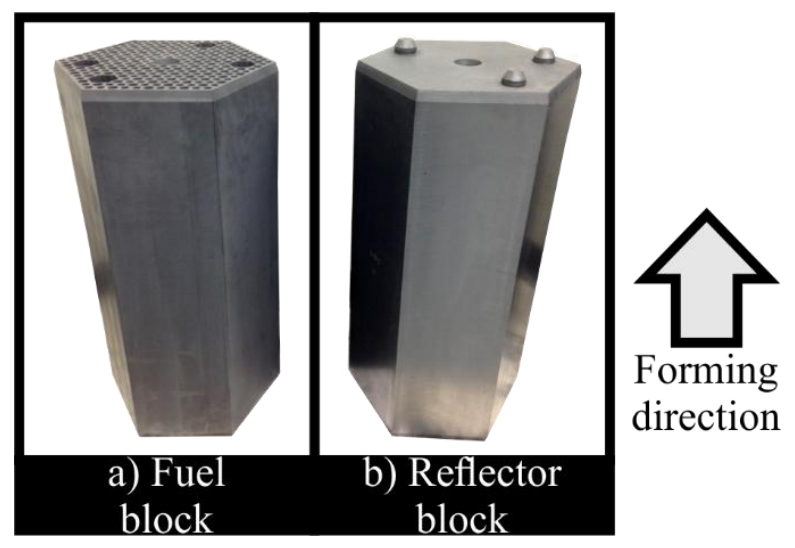

Figure 5. Hexagonal VHTR. a) Fuel block, b) Reflector block

The Young's modulus of this data set was measured in two directions, against-grain and withgrain orientations. For the purpose of this study the data for both directions were combined as one. In order to obtain the desired calculations, the data points were grouped in 4 regions to produce two-dimensional data sets. The centroids of all the samples that are within the same range are aligned in the $\mathrm{x}$-direction; the 4 regions for each group are shown in Figure 8 . An example of how the data points are aligned for Region 1 are shown in Figure 8c and 8d. Table 3 and Table 4 summarise the density and Young's modulus for all the data points and individual regions. These values were used to produce the random fields for NBG-18. 


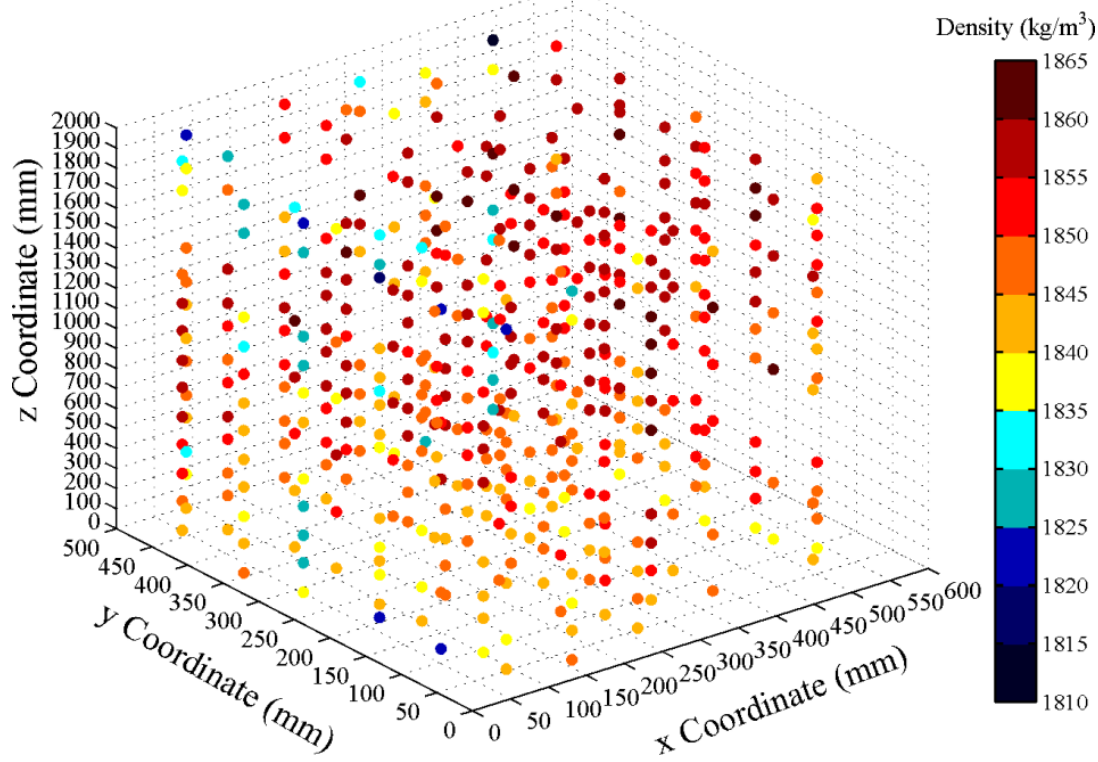

Figure 6. Density map for NBG-18.

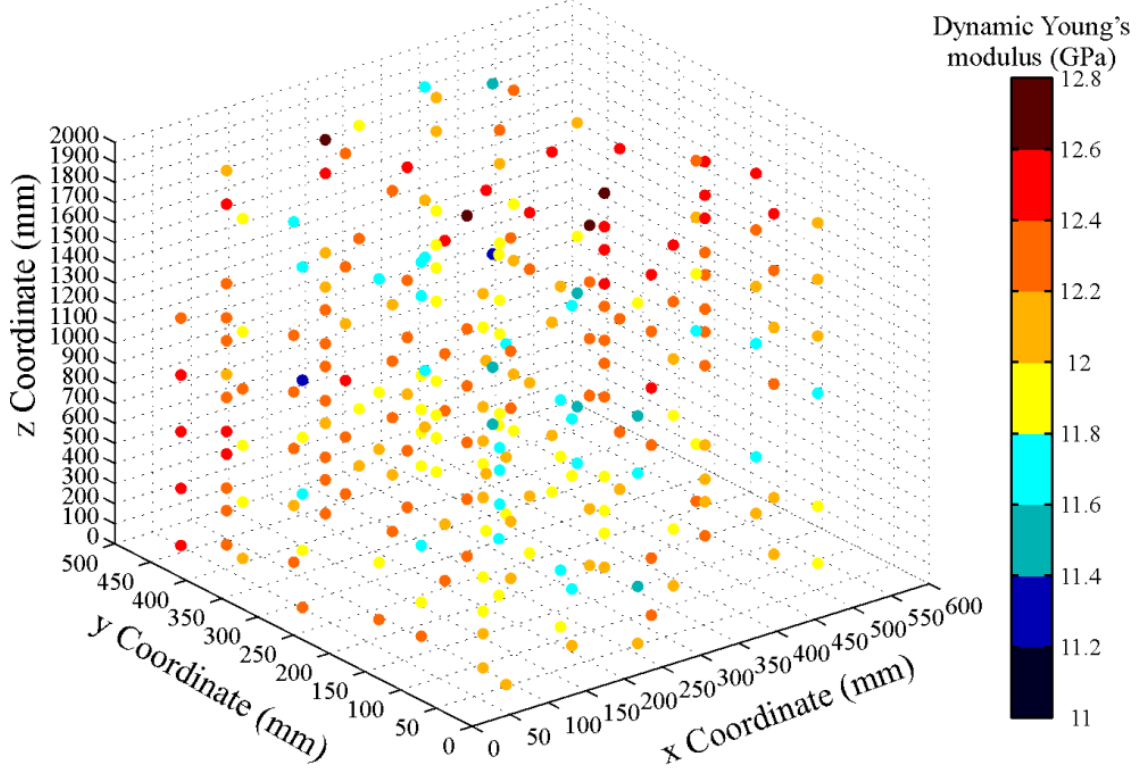

Figure 7. Dynamic Young's modulus map for NBG-18. 


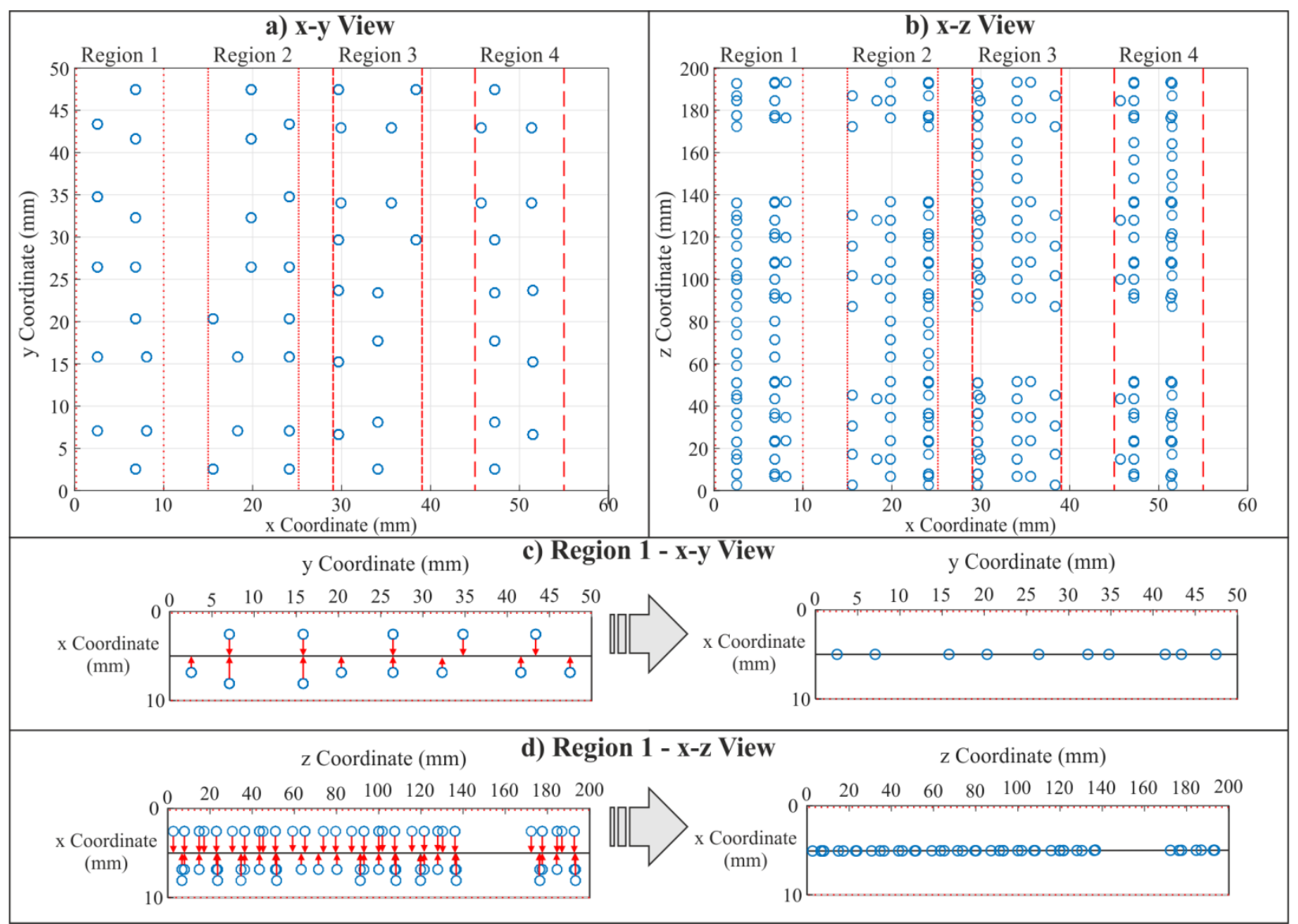

Figure 8. Regions for NBG-18 data. a) $x-y$ View of the regions, b) x-z View of the regions, c) Example of the alignment of data points in the $x$ direction, $x-y$ view for region 1, d) Example of the alignment of data points in the $\mathrm{x}$ direction, $\mathrm{x}-\mathrm{z}$ view for region 1.

Table 3. Mean and standard deviation for density of NBG-18 data.

\begin{tabular}{|c|c|c|c|}
\hline Section & $\begin{array}{l}\text { Density mean } \\
\text { value }\left(\mathrm{kg} / \mathrm{m}^{3}\right)\end{array}$ & $\begin{array}{l}\text { Density standard } \\
\text { deviation }\left(\mathrm{kg} / \mathrm{m}^{3}\right)\end{array}$ & $\begin{array}{c}\text { Number of } \\
\text { samples }\end{array}$ \\
\hline All regions data & 1848.56 & 8.59 & 517 \\
\hline Region 1 & 1842.20 & 9.67 & 119 \\
\hline Region 2 & 1850.81 & 5.93 & 141 \\
\hline Region 3 & 1850.53 & 6.73 & 137 \\
\hline Region 4 & 1849.92 & 9.06 & 119 \\
\hline
\end{tabular}

Table 4. Mean and standard deviation for Young's modulus of NBG-18 data. 


\begin{tabular}{|c|c|c|c|}
\hline Section & $\begin{array}{c}\text { YM mean } \\
\text { direction (GPa) }\end{array}$ & $\begin{array}{c}\text { YM standard } \\
\text { deviation (GPa) }\end{array}$ & $\begin{array}{c}\text { Number of } \\
\text { samples }\end{array}$ \\
\hline All regions data & 12.106 & 0.264 & 253 \\
\hline Region 1 & 12.076 & 0.259 & 63 \\
\hline Region 2 & 12.156 & 0.250 & 65 \\
\hline Region 3 & 12.116 & 0.256 & 71 \\
\hline Region 4 & 12.068 & 0.296 & 54 \\
\hline
\end{tabular}

\section{Methods}

In order to improve the understanding of spatial material variability within a data set it is necessary to create and interpret a variogram. A variogram estimates the shape, correlation length or range, and direction of spatial autocorrelation. The process to create a variogram can be divided into two steps: (1) the first is to calculate an experimental variogram and (2) the second step is to derive a variogram estimator from the experimental variogram. These two steps are known collectively as variography. A comprehensive description of the methodology to generate a variogram and aspects of it can be found in reference [33]. Then, experimental variogram parameters and descriptive statistics of the spatial data are processed to generate random fields for graphite components.

\subsection{Experimental variogram}

The methodology and Matlab software used in this research is contained in the manuscript by Trauth [34]. All calculations were performed using Matlab version R2016a. The general procedure to calculate the experimental variogram is explained in the following steps and in Figure 9:

a) Pair data points. Coordinates and data points for each value of density or Young's modulus are stored in the form of a vector to create 2-D grid coordinates. Then each of these vectors are processed with the Matlab function meshgrid to store the information and pair the data points for the subsequent calculations. A total of 6 matrices are created and called X1, $\mathrm{X} 2, \mathrm{Y} 1, \mathrm{Y} 2, \mathrm{Z} 1, \mathrm{Z} 2$, where $\mathrm{X} 1$ are the coordinates in $\mathrm{x}$ direction $\mathrm{Y} 1$ are the coordinates in $\mathrm{y}$ 
direction, Z1 are the observations of density or Young's modulus and X2, Y2 and Z2 are the transpose matrices of $\mathrm{X} 1, \mathrm{Y} 1$ and $\mathrm{Z} 1$, respectively.

b) Separation distances. Separation distances of each paired data points are calculated with Equation 1 and stored in a matrix called $\mathbf{D}_{\mathbf{T}}$. The individual distances in $\mathbf{D}$ or separation vectors between two points are called lag.

$$
D_{T}=\sqrt{\left(X_{1}+X_{2}\right)^{2}+\left(Y_{1}+Y_{2}\right)^{2}}
$$

c) Semivariances. Individual semivariances are estimated for each paired data points with Equation 2, $h$ represents the lag.

$$
\gamma(h)=\frac{1}{2}\left(Z_{1}-Z_{2}\right)^{2}
$$

d) Initial lag. A minimum distance or lag is determined between points for posterior calculations due to the existence of an uneven grid. This minimum distance is called initial lag and is computed with Equation 3.

$$
\operatorname{lag}_{\min }=\frac{\min (\mathbf{D})}{n}
$$

e) Maximum distance and maximum number of lags. A maximum distance limit is calculated from the D matrix (Equation 4). A good initial estimator of the maximum distance is half of the distance of the largest distance contained in the D matrix. Another important constrain in the calculations is the maximum number of lags, this number is calculated by Equation 5. The maximum number of lags can be obtained by dividing the maximum distance calculated over the initial lag, this value is rounded to obtain an integer number. Both parameters are used to maintain the stability of the variogram and to reduce the number of calculations.

$$
\begin{aligned}
& \text { Max distance }=\frac{\max (D)}{2} \\
& \text { Max lags } \approx \frac{\text { Max distance }_{\text {dag }}}{\text { I }_{\min }}
\end{aligned}
$$


f) Classification of separation distances. An iterative process classifies and calculates the values of variogram estimator.

g) Variogram. The last step consists in plotting the variogram estimators versus the mean separation distances.

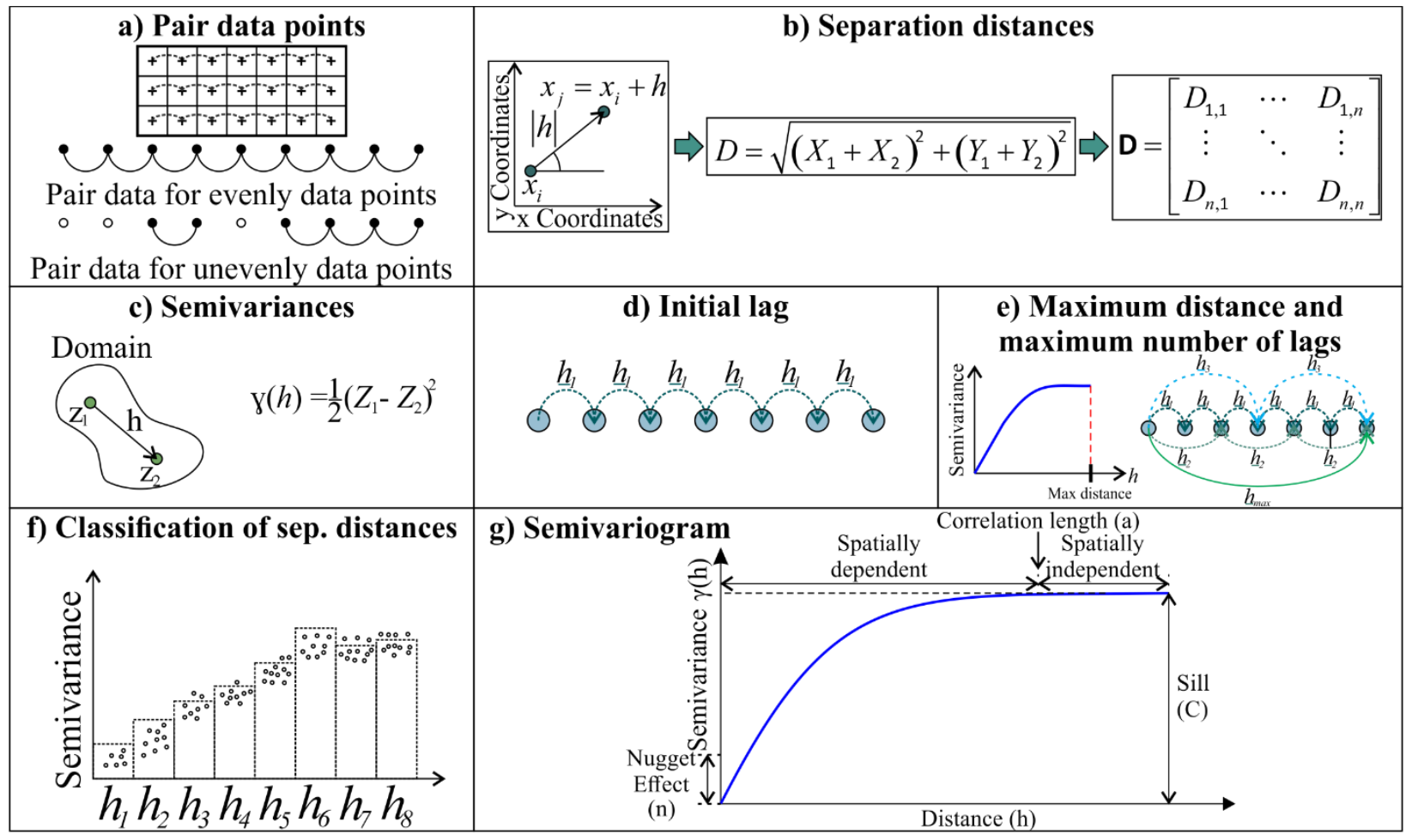

Figure 9. Methodology used to calculate the experimental variogram

To improve the understanding of separation distance and calculation of variogram parameters, a simple one dimensional case is considered. For illustration of this example, a subset of the density measurements of Spine 9 are considred (Figure 10). At the beginning of the calculations the distances between points $\left(\mathrm{Y}_{\mathrm{i}}\right)$ were used to calculate the separation distances (d). Followed by this step the smallest separation distance was assigned as the initial lag $=41.5 \mathrm{~mm}\left(\operatorname{lag}_{\min }\right)$ and the pairing system to calculate the semivariance. All of the calculations are neccesary for the initial semivariance, and the second semivariance calculations (lag $83 \mathrm{~mm}$ ) are summarised in Figure 10 as well as the equation used for one-dimensional analysis. 


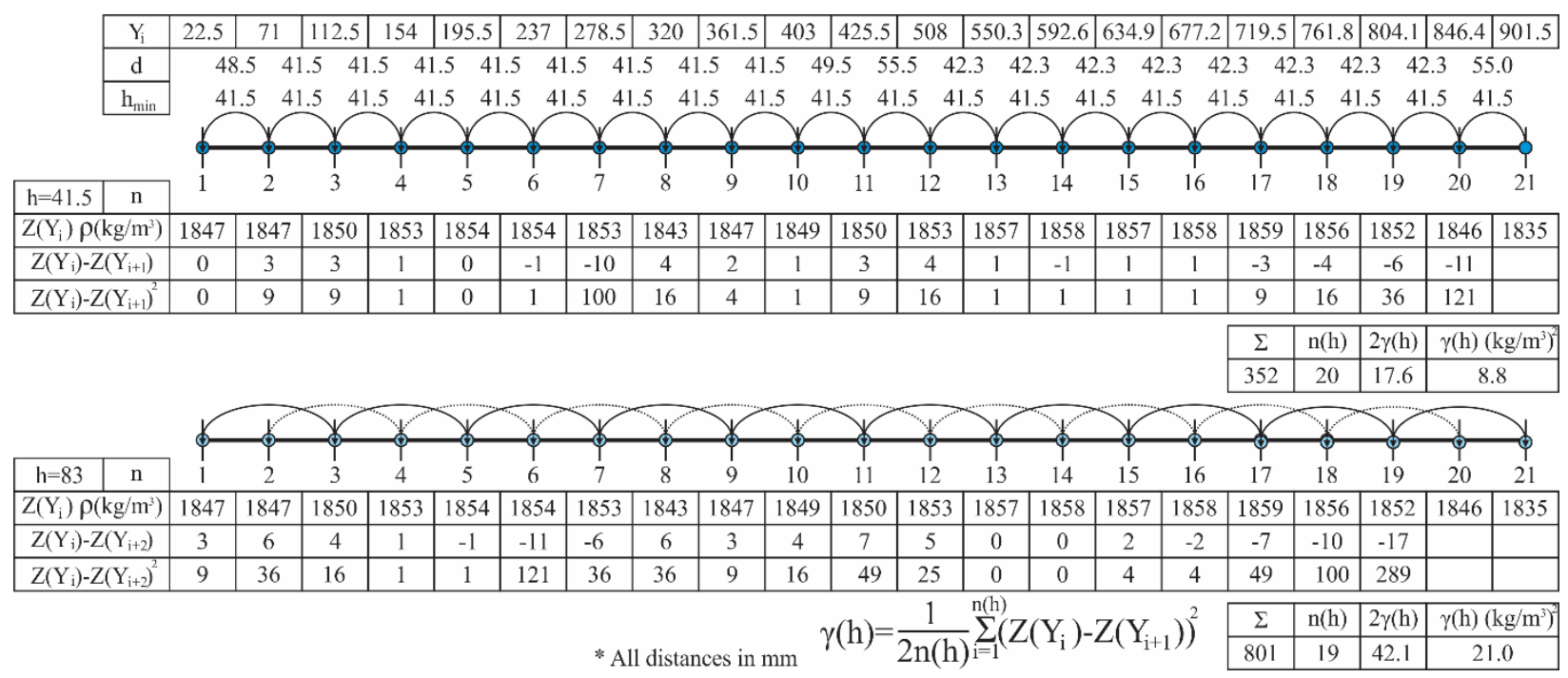

Figure 10. Calculation of a simple variogram of Gilsocarbon density values of Spine 9. $\mathrm{Y}_{\mathrm{i}}-$ coordinates in the y direction, $\mathrm{d}$ - separation distance, $\operatorname{lag}_{\min }$ - minimum lag, $\mathrm{n}(\mathrm{h})$ number of used pairs

\subsection{Variogram estimator}

The experimental variogram plot contains some parameters and features that are important to address. The first important feature is that the variance increases as the lag distance departs from the origin. Variogram models share important parameters that include the nugget effect, the correlation length or range and sill, and these variogram characteristics are shown in Figure 9g.

Nugget effect (n): Ideally this value should be zero $(n=0)$, although some factors can displace the origin of the variogram curve. The nugget effect can also be interpreted as an abrupt change of value at a small distance. This abrupt change is sometimes present in some of the variograms shown in this research.

Correlation length/range ( $\mathbf{L})$ : In context of the variogram this parameter represents the distance in which the variogram reaches a plateau. The range or correlation length is also the distance in which data points larger than this value become spatially uncorrelated. The correlation length can also be interpreted as a measurement that determines the likelihood of finding similar values in a certain range. This behaviour is caused by the fact that points that are paired at larger distances tend to have a lower autocorrelation between them. In other words, a high correlation length means high homogeneity through the material. Examples on the effect of the correlation length 
or range on distribution or variation in property are distributed among 3 realisations of random fields with different correlation length values (Figure 11). The input values to create these realisations were the mean, standard deviation and correlation length. The values chosen for the average and standard deviation came from the density data of Gilsocarbon, and these values are $1834.34 \mathrm{~kg} / \mathrm{m}^{3}$ and $12.19 \mathrm{~kg} / \mathrm{m}^{3}$, respectively.
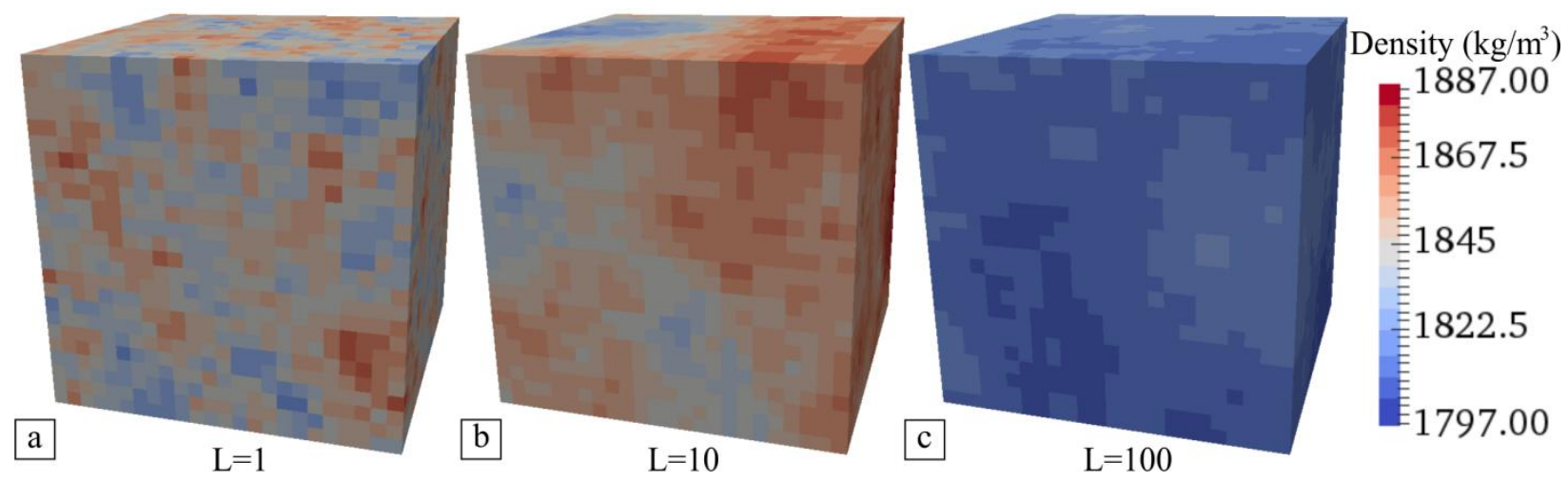

Figure 11 . These cubes have a side length of $100 \mathrm{~mm}$, mean density of $1834.34 \mathrm{~kg} / \mathrm{m}^{3}$ and standard deviation of $12.19 \mathrm{~kg} / \mathrm{m}^{3}$. a) Correlation length of $1 \mathrm{~mm}$, b) Correlation length of 10 $\mathrm{mm}, \mathrm{c})$ Correlation length of $100 \mathrm{~mm}$

Figure 11 illustrates the changes produced by different ranges or correlation lengths. As shown in Figure 11a, the erratic distribution of values of density created by a low correlation length, the low value of correlation length with respect of the cube $(100 \mathrm{~mm})$ create "islands" or spots where the density values are highly correlated. In the case shown in Figure $11 \mathrm{~b}$ it is possible to observe larger patches with similar density values. The last case, Figure 11c presents more smooth transitions of density values through larger distances caused by a higher correlation length value. It is important to mention that a single realisation would not be representative of the possible outcomes of a random field generator.

Sill (C): This parameter is the maximum value that the variogram takes and where the variogram reaches a plateau or tend to become linear. This value is usually close to the variance of the data [35].

A Matlab code by Schwanghart [36] was used to fit a function to the experimental variogram obtained in the last subsection. This code uses a function called variogramfit that requires the 
variogram calculations, desired variogram models and parameters. The code by Schwanghart uses a least square fit to obtain the theoretical variogram from the experimental variogram.

The chosen variogram model for this research was a negative exponential model; the function that describes this model approaches the sill asymptotically. Because of this, the model does not have a practical finite range; however, a practical or effective range is assumed to be equal to 95\% of the sill variance. The exponential model presents a linear behaviour near its origin; this linearity can be used to estimate the sill by plotting a straight line through the first two data points near the origin. Usually the plotted line will intersect the sill at 1/3 of the point where the line intersects with the curve and is called range or correlation length. The equation for the exponential model is given by:

$$
\gamma(h)=n+C_{0}\left[1-e^{\left(\frac{h}{-L}\right)}\right]
$$

where $\mathrm{n}$ is the nugget effect, $\mathrm{C}_{0}$ is the sill, $\mathrm{h}$ is a distance, and $\mathrm{L}$ the correlation length or range. In the following sections two parameters were included, the range $(\mathrm{L})$ and practical range $\left(\mathrm{L}_{\mathrm{P}}\right)$. The practical range is normally the value used in practice. However, the software used in this research estimates the range instead of the practical range. The calculation of the practical range can be approximated by $3 \mathrm{~L}$.

\subsection{Random field generator}

Random fields can be created through several techniques by different processes that can include spatial and/or time variables. In this study, we use a random field generator known as the Local Average Subdivision (LAS) method to represent the spatial variability of density and Young's modulus. Three dimensional random fields are created in this paper, however, for the sake of simplicity the one-dimensional case is explained here. The random field generator for onedimension uses a top-down recursive method. To start the procedure a general mean value is generated for the process. In the first stage, the region is subdivided into two equal subdomains; the subdomains are assigned with a new value that fulfils the condition that the values of each subdomain have to be the mean of the global value (Parent). This process is repeated over and over until the desired refinement of the mesh is achieved (Figure 12). 


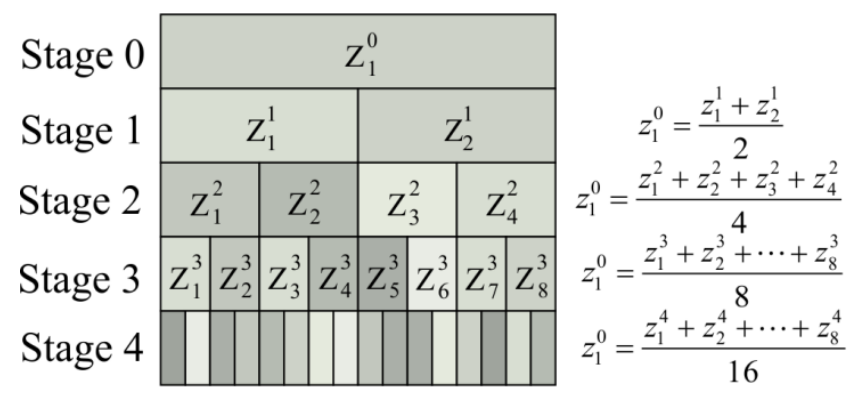

Figure 12. Top-Down Approach, Local Average Subdivision Method Process. The superscript of this image is used to orientate the reader to the parent cell number.

For the full description of the Local Average Subdivision Method random field generator the reader is referred to Reference [37]. The algorithm to create 3D random fields for arbitrary geometries can be found in Reference [10].

The Local Average Subdivision Method requires four inputs: the mean, standard deviation, correlation length and probability distribution. These values can be calculated from raw data; the correlation length can be obtained from variography as was described in the previous two subsections (Subsection 3.1 and 3.2). The data sets for Gilsocarbon and NBG-18 were tested for normality that follows a Gaussian distribution; both cases did not pass the normality tests. In this research a log-normal distribution was assumed for the random field generator. Inputs and outputs for the generation of realisations of a random field are summarised in Figure 13.

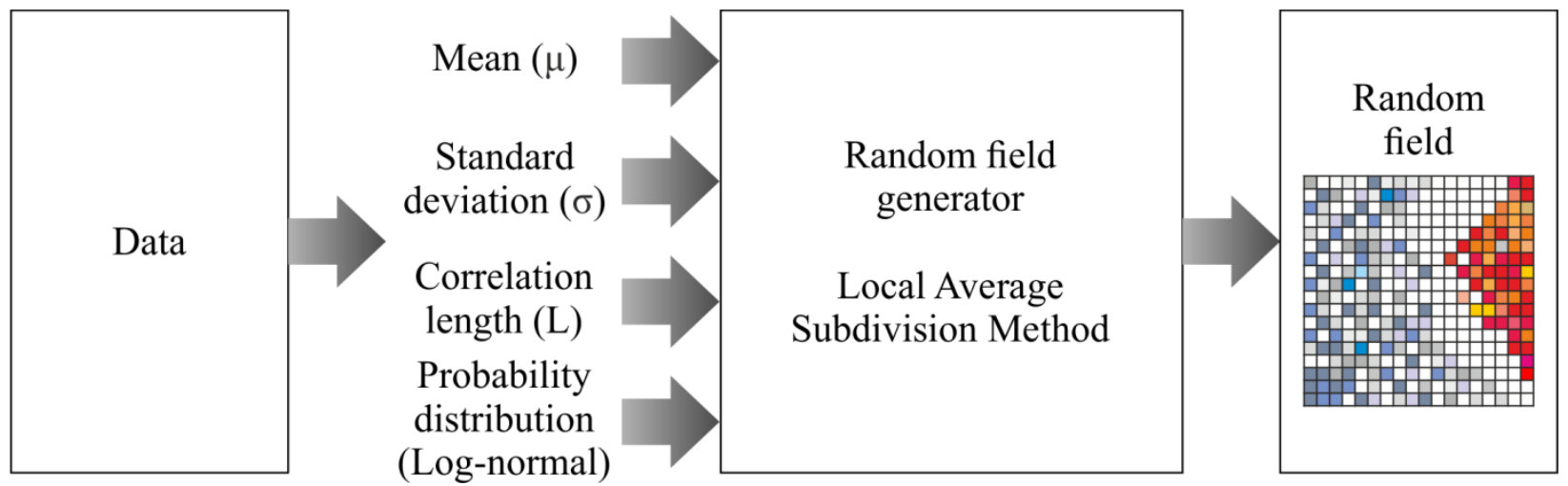

Figure 13. Input values for the Local Average Subdivision (LAS) Method. 


\section{Results}

\subsection{Gilsocarbon density}

The parameters and variograms obtained for the Gilsocarbon density data are summarised in Table 4 and Figure 14. Figure 14 exhibits typical behaviours of variograms in which the semivariance tends to have lower values near the origin and increase with distance until the values tend to reach a plateau (sill). Another indicator of the plateau of the variogram is the population variance included in the plots. Figure 14b and Table 5 show that the largest correlation length or range is found in Spine 6; the lowest correlation length is found in Spine 12. Even though the variogram of Spine 6 does not reach a clear plateau (Figure 14b) it is possible to calculate the variogram parameters by using the fitting parameters obtained from the exponential model.

Table 5. Exponential model parameters for Gilsocarbon density data.

Density exponential model parameters - Gilsocarbon

\begin{tabular}{|c|c|c|c|}
\hline \multicolumn{2}{|c|}{ Spine 3} & \multicolumn{2}{|c|}{ Spine 6} \\
\hline L - Range & 95.58 & L-Range & 277.66 \\
\hline $\mathbf{L}_{\mathbf{P}}$ - Practical range & 286.76 & $\mathrm{~L}_{\mathrm{P}}-$ Practical range & 832.99 \\
\hline c-Sill & 42.02 & $\mathrm{c}-$ Sill & 66.90 \\
\hline n - Nugget effect & $1.73 \times 10^{-8}$ & n-Nugget effect & 12.37 \\
\hline \multicolumn{2}{|c|}{ Spine 9} & \multicolumn{2}{|c|}{ Spine 12} \\
\hline L - Range & 134.11 & L-Range & 76.76 \\
\hline $\mathbf{L}_{\mathbf{P}}$ - Practical range & 402.34 & $\mathrm{~L}_{\mathrm{P}}-$ Practical range & 230.30 \\
\hline c-Sill & 45.31 & $\mathrm{c}-$ Sill & 75.04 \\
\hline n - Nugget effect & $1.67 \times 10^{-8}$ & n - Nugget effect & $1.56 \times 10^{-8}$ \\
\hline
\end{tabular}



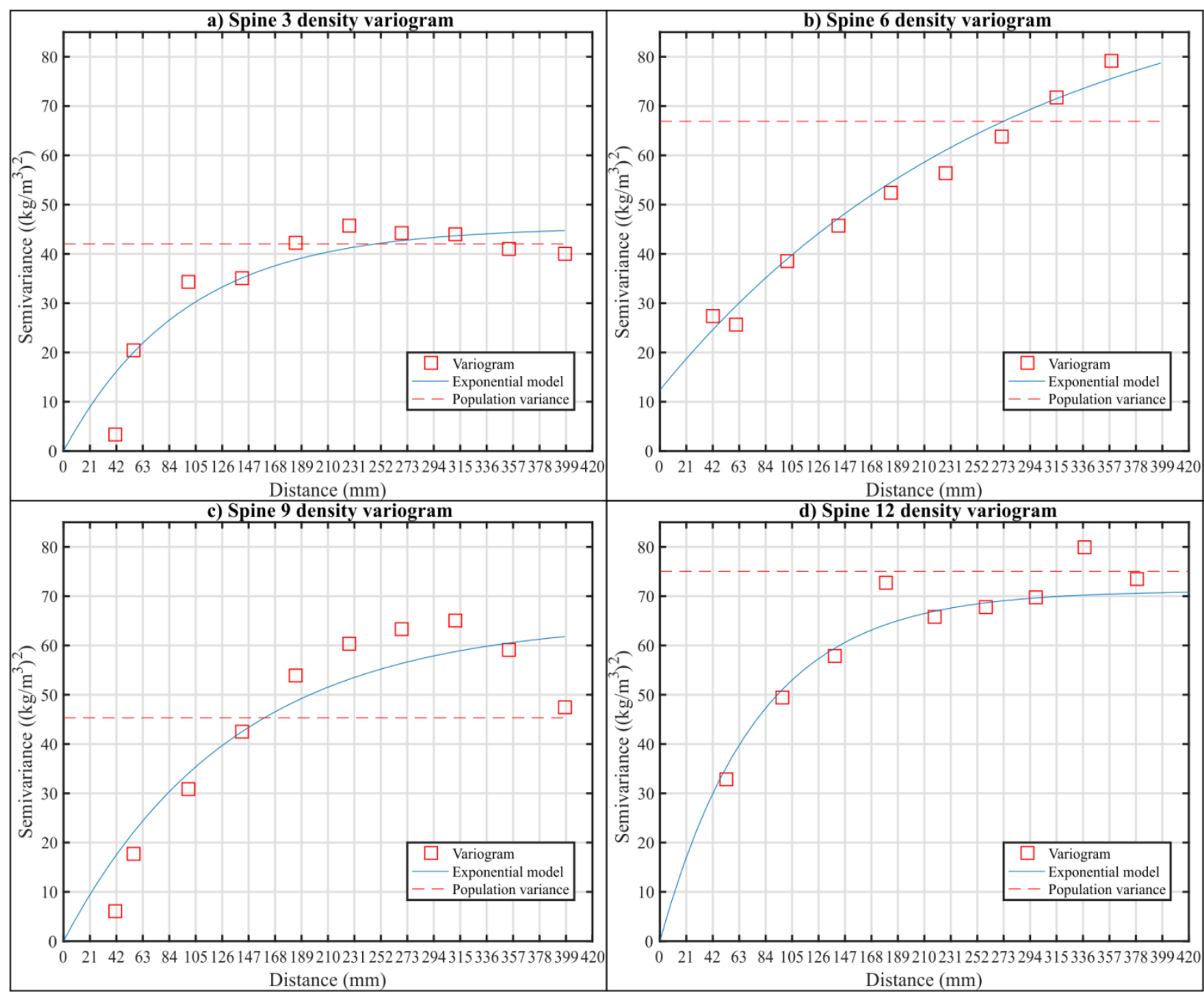

Figure 14. Variograms for Gilsocarbon density data. a) Spine 3 variogram, b) Spine 6 variogram,

c) Spine 9 variogram, d) Spine 12 variogram.

The difference of correlation length and descriptive statistics for density can be better exemplified by the random fields illustrated in Figure 15. Two types of geometries are used to exemplify the variability of the Gilsocarbon data, cubes of $960 \mathrm{~mm}$ side and bricks with geometries similar to Hinkley Point B AGR channel brick designs. Random fields for cubes through all the results sections have a side equal to $960 \mathrm{~mm}$. The geometry for the input parameters for the density random fields were extracted from Table 1 and Table 5 . The practical range or practical correlation length was selected as the parameter correlation length value for the random fields. The use of the practical correlation length as an input parameter for the random field generator is used through all the posterior results sections. 
As was mentioned before, three main parameters control the material property values across a random field that are the mean, standard deviation and correlation length. The influence of these parameters can be seen in the differences between random fields depicted in Figure 15. The mean controls the values around fluctuations in the random fields; this influence can be seen in all the random fields of Figure 15. The next term, the standard deviation can produce larger fluctuations around the mean value if this value is high enough. An example of these variations can be found in Figure 15d and Figure 15h. Finally, the correlation length can have two effects on the generation of random fields. Smaller correlation lengths produce a concentration of highly correlated sections of the random field (Figure 15c and Figure 15d), whereas larger correlation lengths produce more smooth variations on the values of a random field (Figure 15b). Figure 15e to Figure $15 \mathrm{~h}$ show how random fields can also be used to simulate the spatial variability in complex geometries such as an AGR component. Much of the variation of density in the random field for the brick of Spine 12 data can be explained by the low value of correlation length (Figure 15h). A more homogenous distribution of material properties can be found in Figure 15e and Figure 15f. 

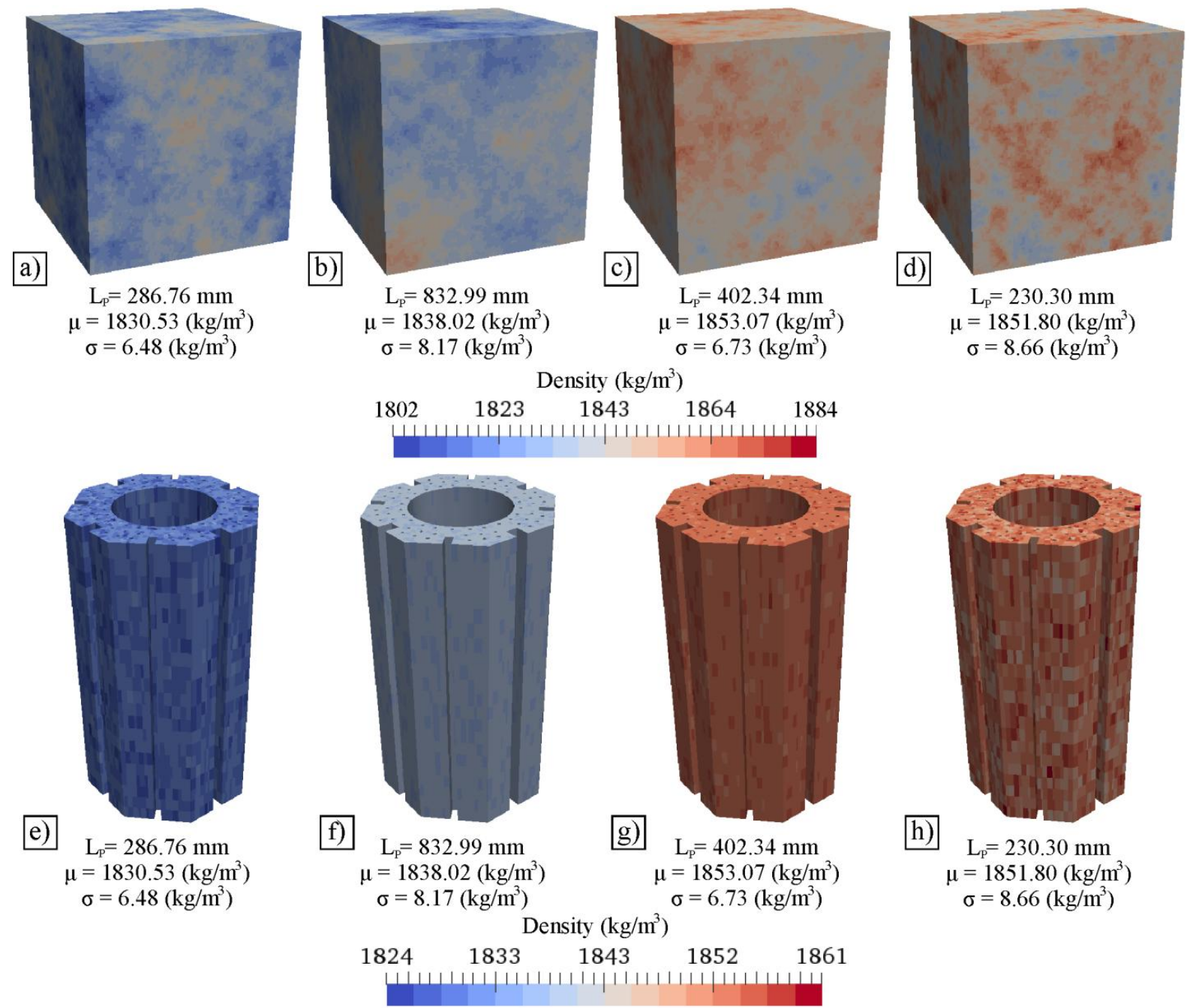

Figure 15. Random fields for Gilsocarbon density data, the length of the sides of the cubes is 960 $\mathrm{mm}$ and show the effect of different correlation lengths on density values. a) Random field cube - Spine 3, b) Random field - cube - Spine 6, c) Random field - cube - Spine 9, d) Random field - cube - Spine 12, e) Random field - graphite brick - Spine 3, f) Random field - graphite brick - Spine 6, g) Random field - graphite brick - Spine 9, h) Random field - graphite brick -

Spine 12.

\subsection{Gilsocarbon Young's modulus}

Table 6 provides the results for Young's modulus for the Gilsocarbon data set, the correlation length or range values for the same spine and different direction show similar values between them. 
The highest value for correlation length can be found in Spine 6; this trend is also found for the density value of Spine 6. In this case the lowest correlation length value corresponds to Spine 9. Only the variograms for Young's modulus in the $\mathrm{x}$ direction are included in this study and are shown in Figure 16.

As with the previous Gilsocarbon density results, a random field was generated for each calculated correlation length (Figure 17). In general, these random fields present similar patterns as the ones found in Figure 15. This resemblance is expected because of the relationship between density and Young's modulus values [32, 38]: graphite denser areas tend to be stiffer. This fact follows a trend found by an empirical relationship proposed by Yoda and Fujisaki [39] between density and Young's modulus. This research shows how low values of coefficient of thermal expansion (CTE) and Young's modulus correspond to specimens with low density. The random fields for Figures 17a and 17b display the smallest spatial variations of Young's modulus, this behaviour is due to the small standard deviation in the case of Figure 17a and large correlation length value in the case of Figure 17b. Random fields for AGR bricks are found in Figure 17e to Figure 17h. The most homogeneous Young's modulus random field for AGR bricks is shown in Figure 17f; this is likely to be produce by the large correlation length found in Spine 6. Closer inspection of the random fields for graphite bricks indicate that the most spatial material variability can be found in Figure $17 \mathrm{~g}$. This behaviour is perhaps caused by the low value for the correlation length in Spine 9. 
Table 6. Exponential model parameters for Gilsocarbon Young's modulus in the $\mathrm{x}$ direction data

Young's modulus exponential model parameters - Gilsocarbon

\begin{tabular}{|c|c|c|c|}
\hline \multicolumn{4}{|c|}{ Young's modulus $\mathrm{x}$ direction } \\
\hline \multicolumn{2}{|c|}{ Spine 3} & \multicolumn{2}{|c|}{ Spine 6} \\
\hline L - Range & 133.80 & L - Range & 380.14 \\
\hline $\mathbf{L}_{\mathbf{P}}-$ Practical range & 401.40 & $\mathbf{L}_{\mathbf{P}}-$ Practical range & 1140.42 \\
\hline c-Sill & 0.03 & c-Sill & 0.12 \\
\hline$n$ - Nugget effect & 0.007 & $n$ - Nugget effect & 0.05 \\
\hline \multicolumn{2}{|c|}{ Spine 9} & \multicolumn{2}{|c|}{ Spine 12} \\
\hline L - Range & 68.21 & L - Range & 120.68 \\
\hline $\mathbf{L}_{\mathbf{P}}-$ Practical range & 204.63 & $\mathbf{L}_{\mathbf{P}}-$ Practical range & 362.04 \\
\hline c-Sill & 0.03 & c-Sill & 0.06 \\
\hline n - Nugget effect & $1.02 \times 10^{-12}$ & $n$ - Nugget effect & 0.004 \\
\hline \multicolumn{4}{|c|}{ Young's modulus y direction } \\
\hline \multicolumn{2}{|c|}{ Spine 3} & \multicolumn{2}{|c|}{ Spine 6} \\
\hline L - Range & 117.17 & L - Range & 327.31 \\
\hline $\mathbf{L}_{\mathbf{P}}-$ Practical range & 351.51 & $\mathbf{L}_{\mathbf{P}}-$ Practical range & 981.93 \\
\hline c-Sill & 0.08 & c-Sill & 0.13 \\
\hline$n$ - Nugget effect & $5.11 \times 10^{-12}$ & n-Nugget effect & 0.04 \\
\hline \multicolumn{2}{|c|}{ Spine 9} & \multicolumn{2}{|c|}{ Spine 12} \\
\hline L - Range & 82.71 & L - Range & 125.62 \\
\hline $\mathbf{L}_{\mathbf{P}}-$ Practical range & 248.13 & $\mathbf{L}_{\mathbf{P}}-$ Practical range & 376.86 \\
\hline c-Sill & 0.05 & c-Sill & 0.08 \\
\hline$n$ - Nugget effect & $1.19 \times 10^{-12}$ & n- Nugget effect & $3.05 \times 10^{-11}$ \\
\hline \multicolumn{4}{|c|}{ Young's modulus z direction } \\
\hline \multicolumn{2}{|c|}{ Spine 3} & \multicolumn{2}{|c|}{ Spine 6} \\
\hline L - Range & 146.62 & L - Range & 403.88 \\
\hline $\mathbf{L}_{\mathbf{P}}-$ Practical range & 439.86 & $\mathbf{L}_{\mathbf{P}}-$ Practical range & 1211.64 \\
\hline c-Sill & 0.06 & c-Sill & 0.07 \\
\hline n - Nugget effect & 0.003 & n - Nugget effect & 0.03 \\
\hline \multicolumn{2}{|c|}{ Spine 9} & \multicolumn{2}{|c|}{ Spine 12} \\
\hline L - Range & 82.46 & L - Range & 131.44 \\
\hline $\mathbf{L}_{\mathbf{P}}-$ Practical range & 247.38 & $\mathbf{L}_{\mathbf{P}}-$ Practical range & 394.32 \\
\hline c-Sill & 0.04 & c-Sill & 0.07 \\
\hline n- Nugget effect & $6.09 \times 10^{-12}$ & n- Nugget effect & 0.001 \\
\hline
\end{tabular}



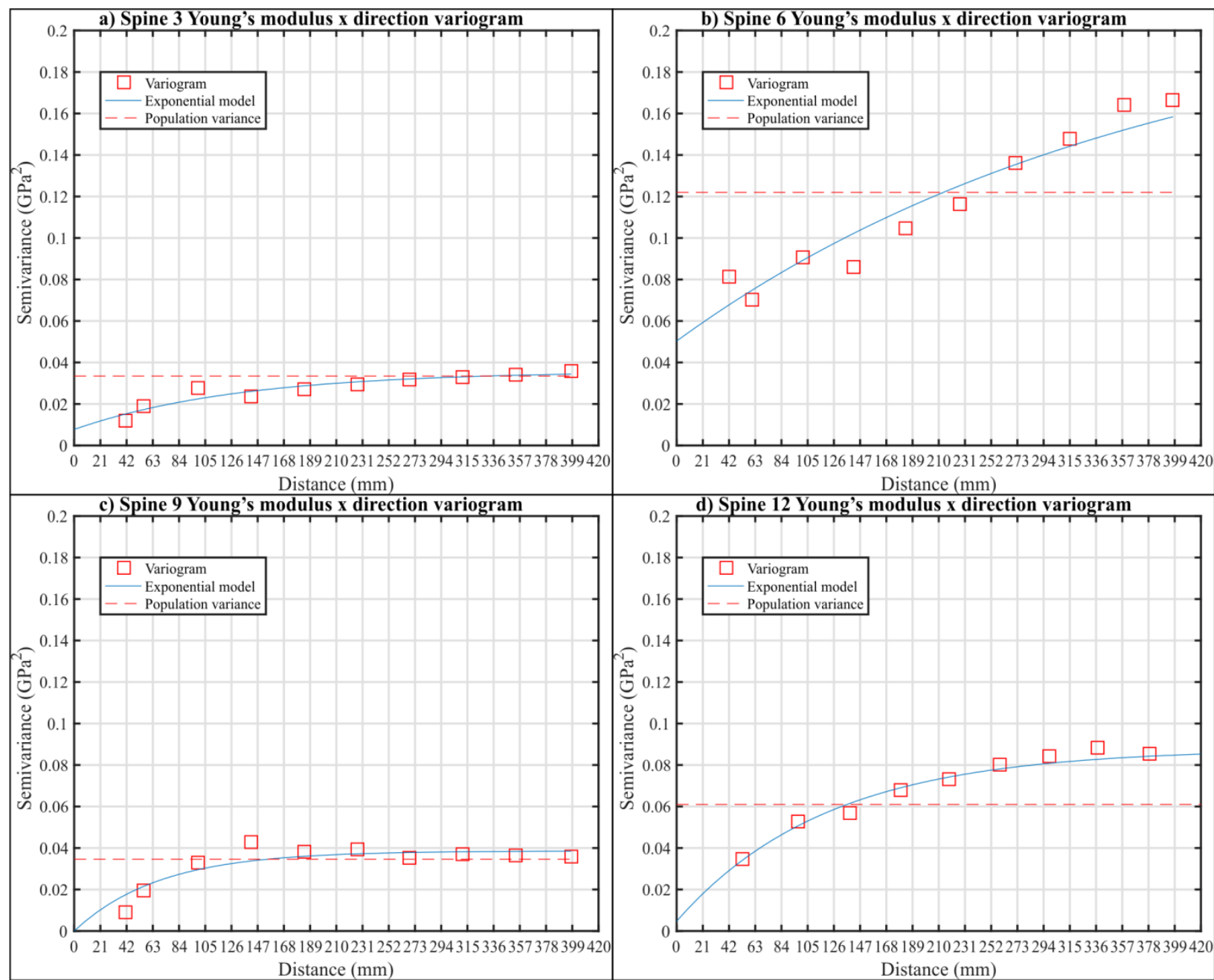

Figure 16. Variograms for Gilsocarbon Young's modulus in x direction. a) Spine 3 variogram, b) Spine 6 variogram, c) Spine 9 variogram, d) Spine 12 

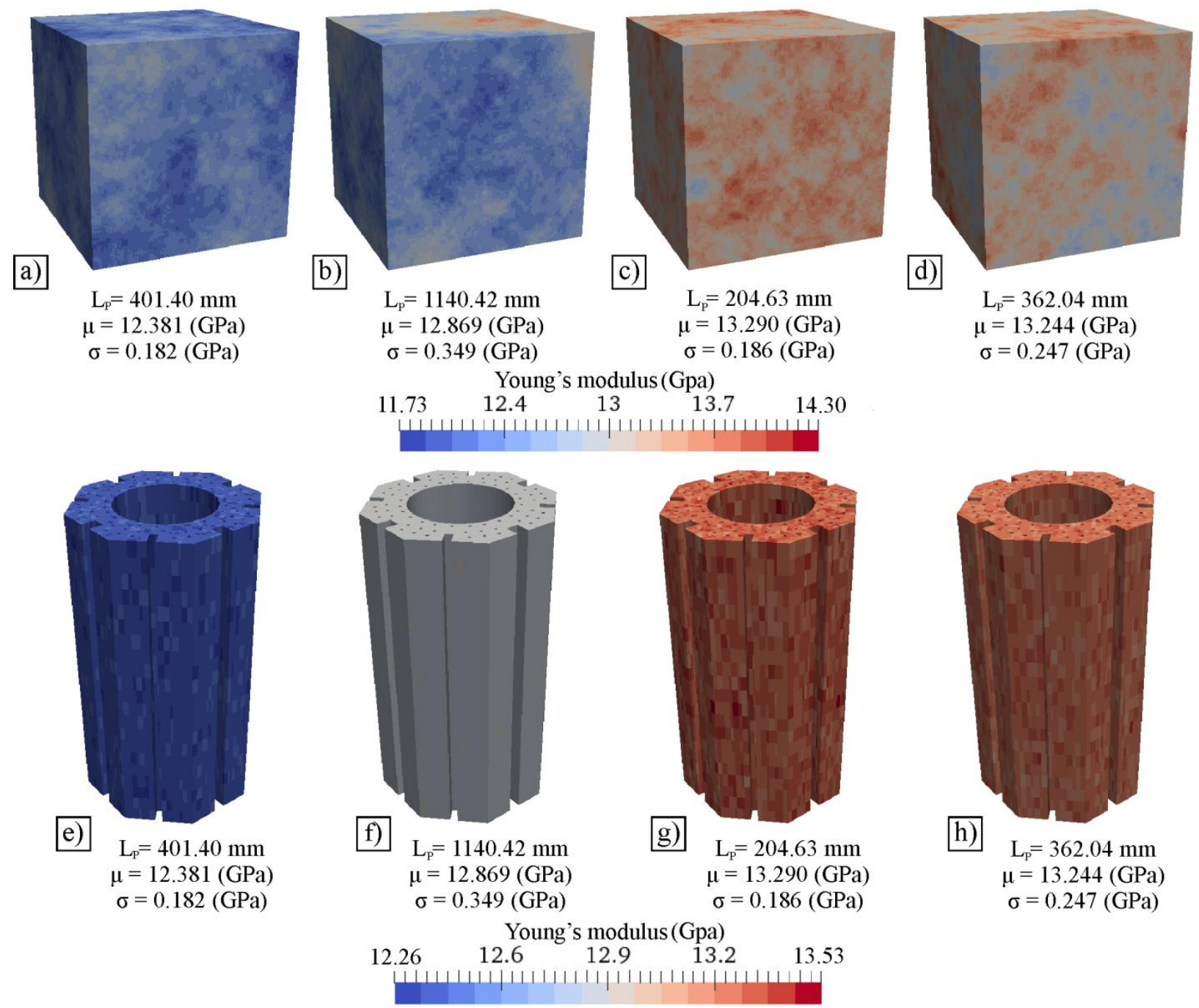

Figure 17. Random fields for Young's modulus data in the $\mathrm{x}$ direction, the length of the sides of the cubes is $960 \mathrm{~mm}$ and show the effect of different correlation lengths on Young's modulus values. a) Random field - cube - Spine 3, b) Random field - cube - Spine 6, c) Random field cube - Spine 9, d) Random field - cube - Spine 12, e) Random field - graphite brick - Spine 3,

f) Random field - graphite brick - Spine 6, g) Random field - graphite brick - Spine 9, h)

Random field - graphite brick - Spine 12

\subsection{NBG-18 density}

NBG-18 density variography results are outlined in Table 7 and Figure 18. Compared to the Gilsocarbon density results, the NBG-18 ranges or correlation lengths are very similar between Region 1 to Region 3 as can be seen in Table 7. Even though the variograms depicted in Figure 
18 present different characteristics, the range or correlation length are alike for the first three cases. The poor fit of the exponential model in Figure 18a and Figure 18d can be explained by the scatter of calculated semivariance and possible outliers that are close to the edge or centre of the billet where high variations of density and Young's modulus are expected (Figure 6 and Figure 7).

These results also suggest that the spatial variability in NBG-18 is of short order for Regions 1 to Region 3. The low values of correlation length found in Region 1 to Region 3 (179 to $272 \mathrm{~mm}$ ) and the large correlation length at Region $4(828 \mathrm{~mm})$ mean that dissimilar density values can likely to be found through the ends of the billet.

Table 7. Exponential model parameters for NBG-18 density data

Density exponential model parameters - NBG-18

$$
\gamma(h)=n+c\left(1-e^{\left(\frac{-h}{L}\right)}\right)
$$

\begin{tabular}{|c|c|c|c|}
\hline \multicolumn{2}{|c|}{ Region 1} & \multicolumn{2}{|c|}{ Region 2} \\
\hline L - Range & 83.27 & L - Range & 90.97 \\
\hline $\mathbf{L}_{\mathbf{P}}$ - Practical range & 249.83 & $\mathbf{L}_{\mathbf{P}}-$ Practical range & 272.91 \\
\hline c-Sill & 93.61 & c-Sill & 35.23 \\
\hline n - Nugget effect & 36.53 & n - Nugget effect & 14.36 \\
\hline \multicolumn{2}{|c|}{ Region 3} & \multicolumn{2}{|c|}{ Region 4} \\
\hline L - Range & 59.67 & L - Range & 276.25 \\
\hline $\mathbf{L}_{\mathbf{P}}$ - Practical range & 179.01 & $\mathbf{L}_{\mathbf{P}}$ - Practical range & 828.75 \\
\hline c-Sill & 45.29 & c-Sill & 82.10 \\
\hline n - Nugget effect & 11.80 & n - Nugget effect & 55.49 \\
\hline
\end{tabular}

Further analysis was performed by producing a series of random fields that represent the spatial material variability of the NBG-18 density data (Figure 19). All the random fields present a similar behaviour on the distribution of material properties, but only the random field for Region 1 have lower values due to the lower mean of this region. A very similar behaviour can be found in the case of graphite bricks; again, the random fields for Regions 2 to 3 present a homogenous 
spatial distribution around their means and Region 1 shows a similar pattern but with lower density values. On the other hand, Region 4 presents a more homogeneous distribution due to the larger correlation length found in this location.
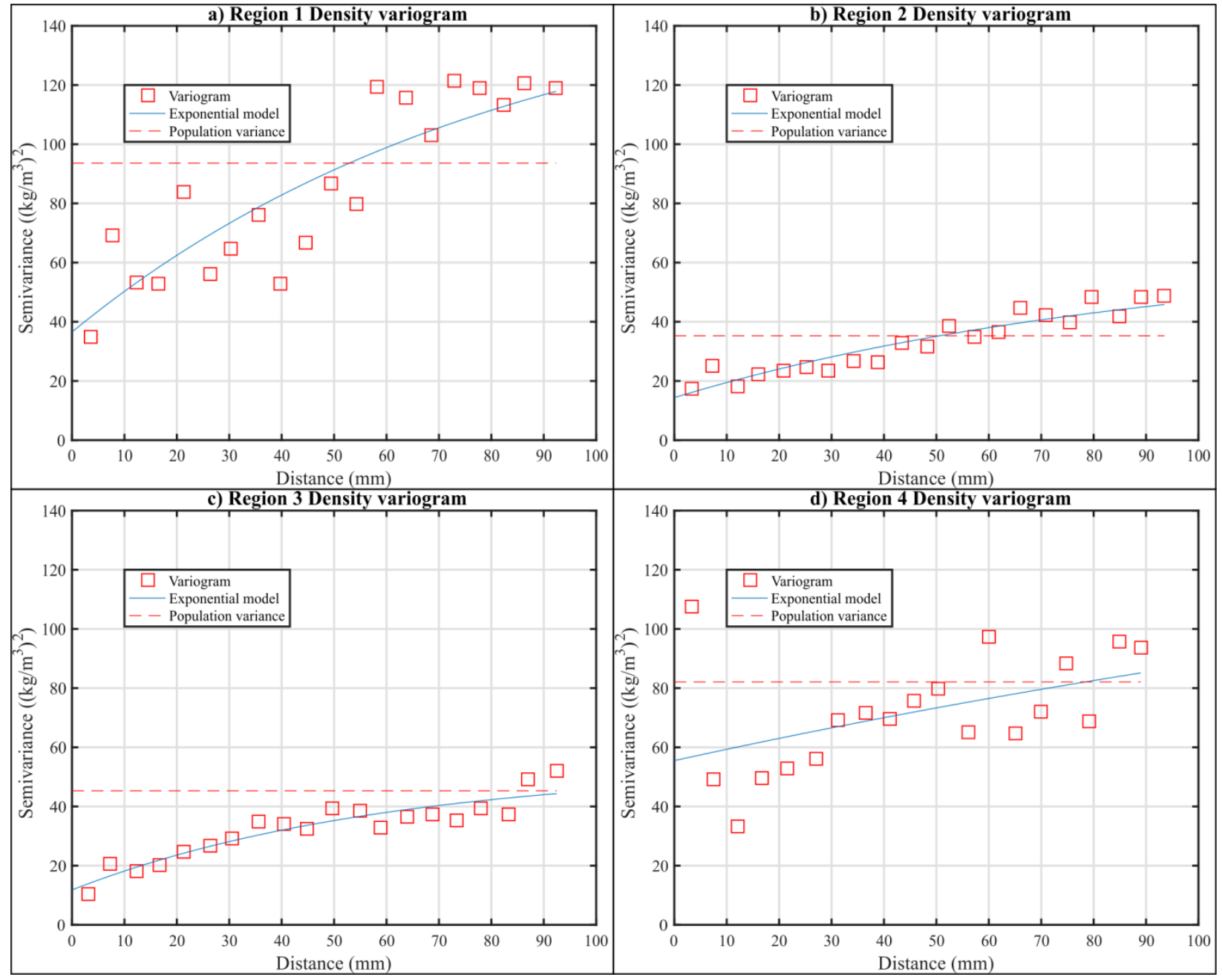

Figure 18. Variograms for NBG-18 density data. a) Region 1 variogram, b) Region 2 variogram, c) Region 3 variogram, d) Region 4 variogram 


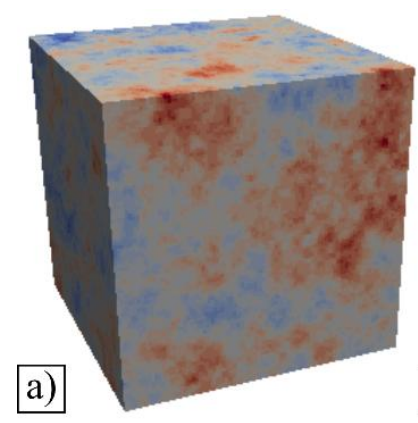

$\mathrm{L}_{\mathrm{P}}=249.83 \mathrm{~mm}$ $\mu=1842.20\left(\mathrm{~kg} / \mathrm{m}^{3}\right)$ $\sigma=9.67\left(\mathrm{~kg} / \mathrm{m}^{3}\right)$

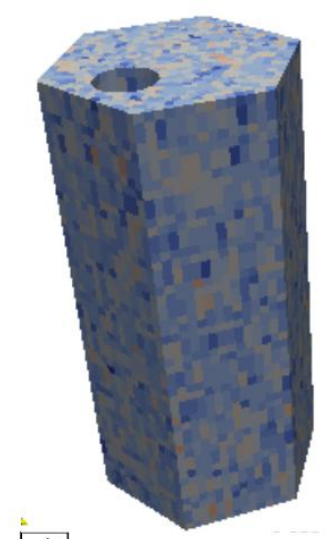

e)

$\mathrm{L}_{\mathrm{P}}=249.83 \mathrm{~mm}$ $\mu=1842.20\left(\mathrm{~kg} / \mathrm{m}^{3}\right)$ $\sigma=9.67\left(\mathrm{~kg} / \mathrm{m}^{3}\right)$

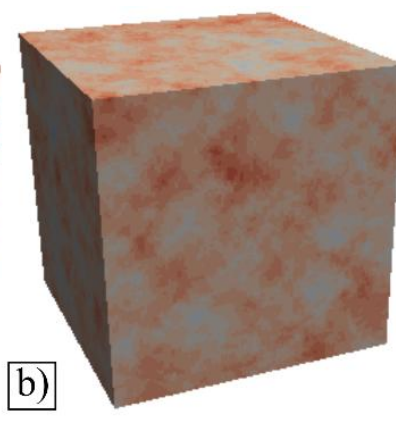

$$
\begin{gathered}
\mathrm{L}_{\mathrm{P}}=272.91 \mathrm{~mm} \\
\mu=1850.81\left(\mathrm{~kg} / \mathrm{m}^{3}\right) \\
\sigma=5.93\left(\mathrm{~kg} / \mathrm{m}^{3}\right)
\end{gathered}
$$

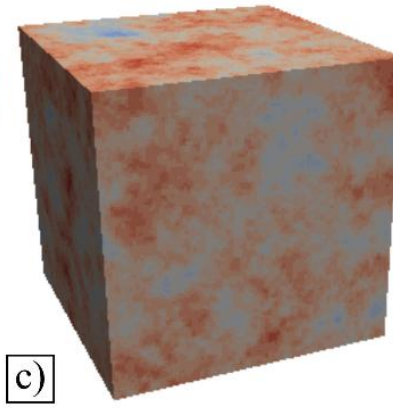

c)

$$
\begin{gathered}
\mathrm{L}_{\mathrm{P}}=179.01 \mathrm{~mm} \\
\mu=1850.53\left(\mathrm{~kg} / \mathrm{m}^{3}\right) \\
\sigma=6.73\left(\mathrm{~kg} / \mathrm{m}^{3}\right)
\end{gathered}
$$

Density $\left(\mathrm{kg} / \mathrm{m}^{3}\right)$
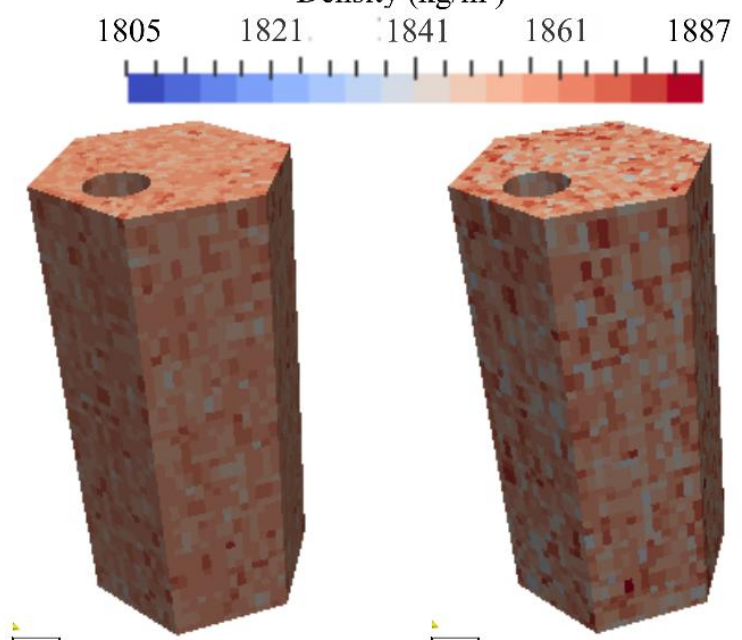

f)

$$
\begin{gathered}
\mathrm{L}_{\overline{\mathrm{P}}}=272.91 \mathrm{~mm} \\
\mu=1850.81\left(\mathrm{~kg} / \mathrm{m}^{3}\right) \\
\sigma=5.93\left(\mathrm{~kg} / \mathrm{m}^{3}\right)
\end{gathered}
$$

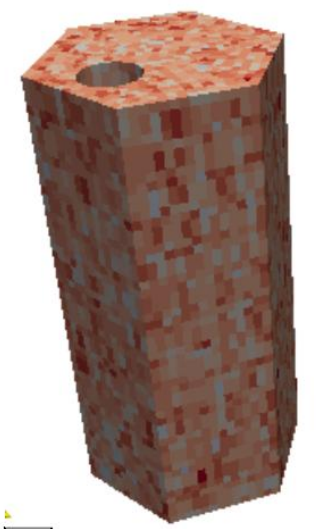

g)

$$
\begin{gathered}
\mathrm{L}_{\mathrm{P}}=179.01 \mathrm{~mm} \\
\mu=1850.53\left(\mathrm{~kg} / \mathrm{m}^{3}\right) \\
\sigma=6.73\left(\mathrm{~kg} / \mathrm{m}^{3}\right)
\end{gathered}
$$

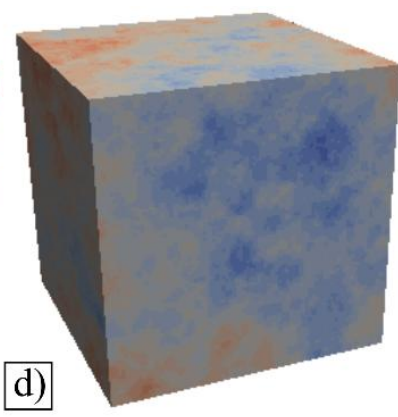

$\mathrm{L}_{\mathrm{P}}=828.75 \mathrm{~mm}$ $\mu=1849.92\left(\mathrm{~kg} / \mathrm{m}^{3}\right)$ $\sigma=9.06\left(\mathrm{~kg} / \mathrm{m}^{3}\right)$

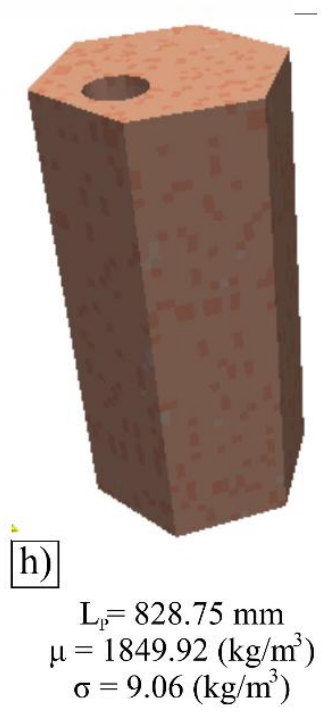

Figure 19. Random fields for NBG-18 density data, the length of the sides of the cubes is 960 $\mathrm{mm}$ and show the effect of different correlation lengths on density values. a) Random field cube - Region 1, b) Random field - cube - Region 2, c) Random field - cube - Region 3, d)

Random field - cube - Region 4, e) Random field - graphite brick - Region 1, f) Random field graphite brick - Region 2, g) Random field - graphite brick - Region 3, h) Random field graphite brick - Region 4. 


\subsection{NBG-18 Young's modulus}

Parameters for the exponential model of NBG-18 Young's modulus data are summarised in Table 8. Notably, in Table 8 all of the range or correlation length values show the same patterns than the density correlations length values. This means that the same trends for correlation length values are followed between the density and Young's modulus calculations. Although the trends between density and Young's modulus correlation length values are similar their respective variograms are not (Figure 18 and Figure 20). Two explanations are proposed, first outliers in the original data and possible microstructural effects. Semivariance outlier points can be specially observed in Figure 18a, Figure 18d, Figure 20b and Figure 20d. These outliers may be produced by the material property variations found across the billet (Figure 6 and 7). The second possible explanation is that the microstructure of NBG-18, as the grain size and defects found in the specimen influence the Young's modulus values at localised areas.

The largest correlation length value found for Young's modulus was $252.39 \mathrm{~mm}$. Again, this fact can be interpreted as a short-range-order distribution of this material property across the NBG-18 billet. Variograms for NBG-18 Young's modulus data are shown in Figure 20.

Figure 20 shows the respective variograms of Young's modulus for each region of the NBG-18 billet. A comparison between the population variance plotted in Figure 20 and range or correlation length of Table 8 indicate that share similar values except for Region 4. As with previous results random fields were generated for the NBG-18 Young's modulus data (Figure 21). The random fields represented in this illustration show interesting patterns because of the different spatial distributions. Lower correlation lengths were found in Region 1 and Region 2 whereas larger correlation lengths can be seen in Region 3 and Region 4. 
Table 8. Exponential model parameters for NBG-18 Young's modulus data

Young's modulus exponential model parameters - NBG-18

$$
\gamma(h)=n+c\left(1-e^{\left(\frac{-h}{L}\right)}\right)
$$

\begin{tabular}{|c|c|c|c|}
\hline \multicolumn{2}{|c|}{ Region 1} & \multicolumn{2}{|c|}{ Region 2} \\
\hline L - Range & 7.94 & L - Range & 18.87 \\
\hline $\mathbf{L}_{P}$ - Practical range & 23.82 & $\mathbf{L}_{\mathbf{P}}$ - Practical range & 56.61 \\
\hline c-Sill & 0.06 & c-Sill & 0.06 \\
\hline n - Nugget effect & $2.08 \times 10^{-12}$ & n - Nugget effect & $7.66 \times 10^{-12}$ \\
\hline \multicolumn{2}{|c|}{ Region 3} & \multicolumn{2}{|c|}{ Region 4} \\
\hline L - Range & 55.65 & L - Range & 84.13 \\
\hline $\mathbf{L}_{\mathbf{P}}$ - Practical range & 166.95 & $\mathbf{L}_{\mathbf{P}}$ - Practical range & 252.39 \\
\hline c-Sill & 0.06 & c - Sill & 0.08 \\
\hline n - Nugget effect & 0.01 & n - Nugget effect & 0.03 \\
\hline
\end{tabular}



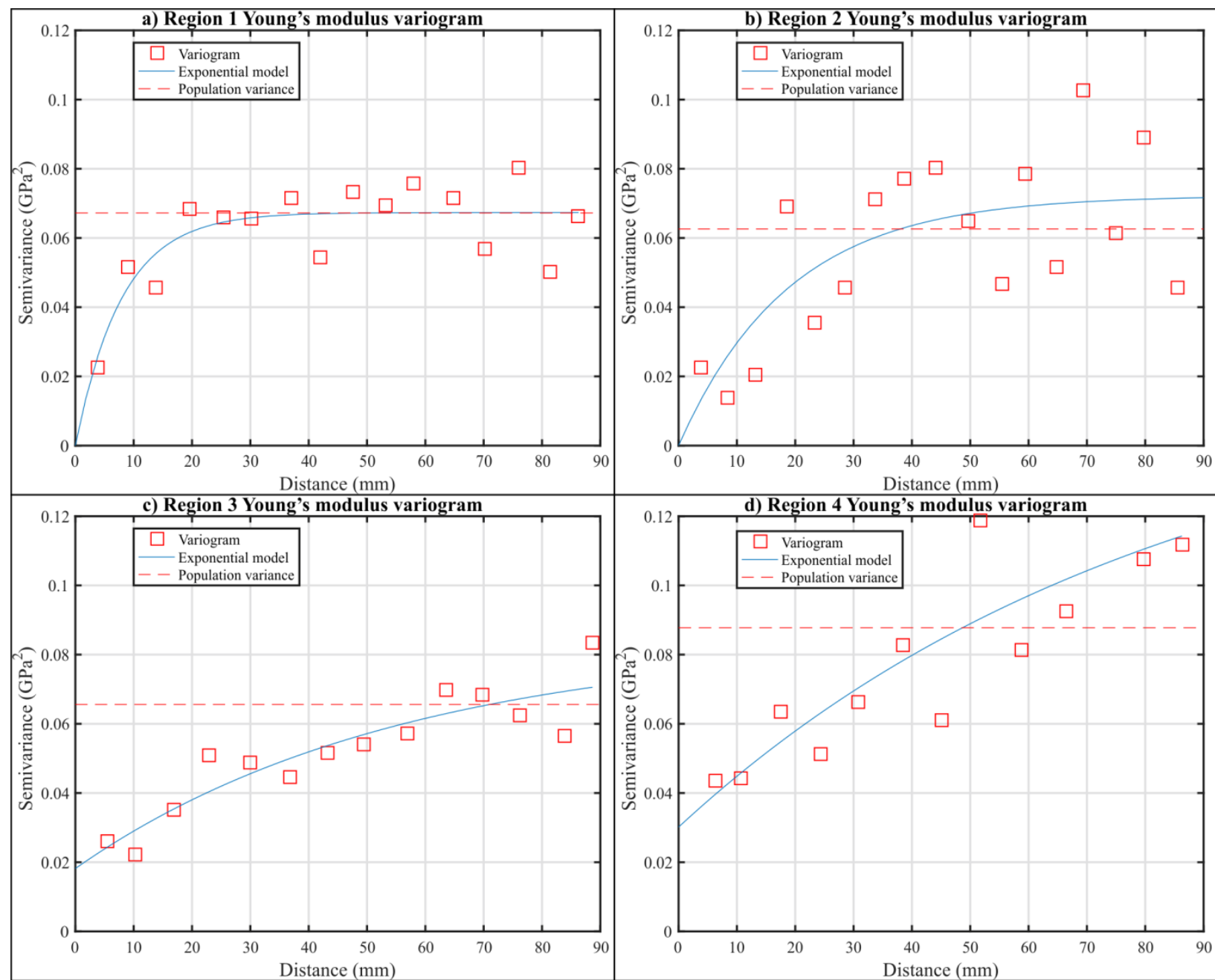

Figure 20. Variograms for NBG-18 Young's modulus. a) Region 1 variogram, b) Region 2 variogram, c) Region 3 variogram, d) Region 4 variogram 

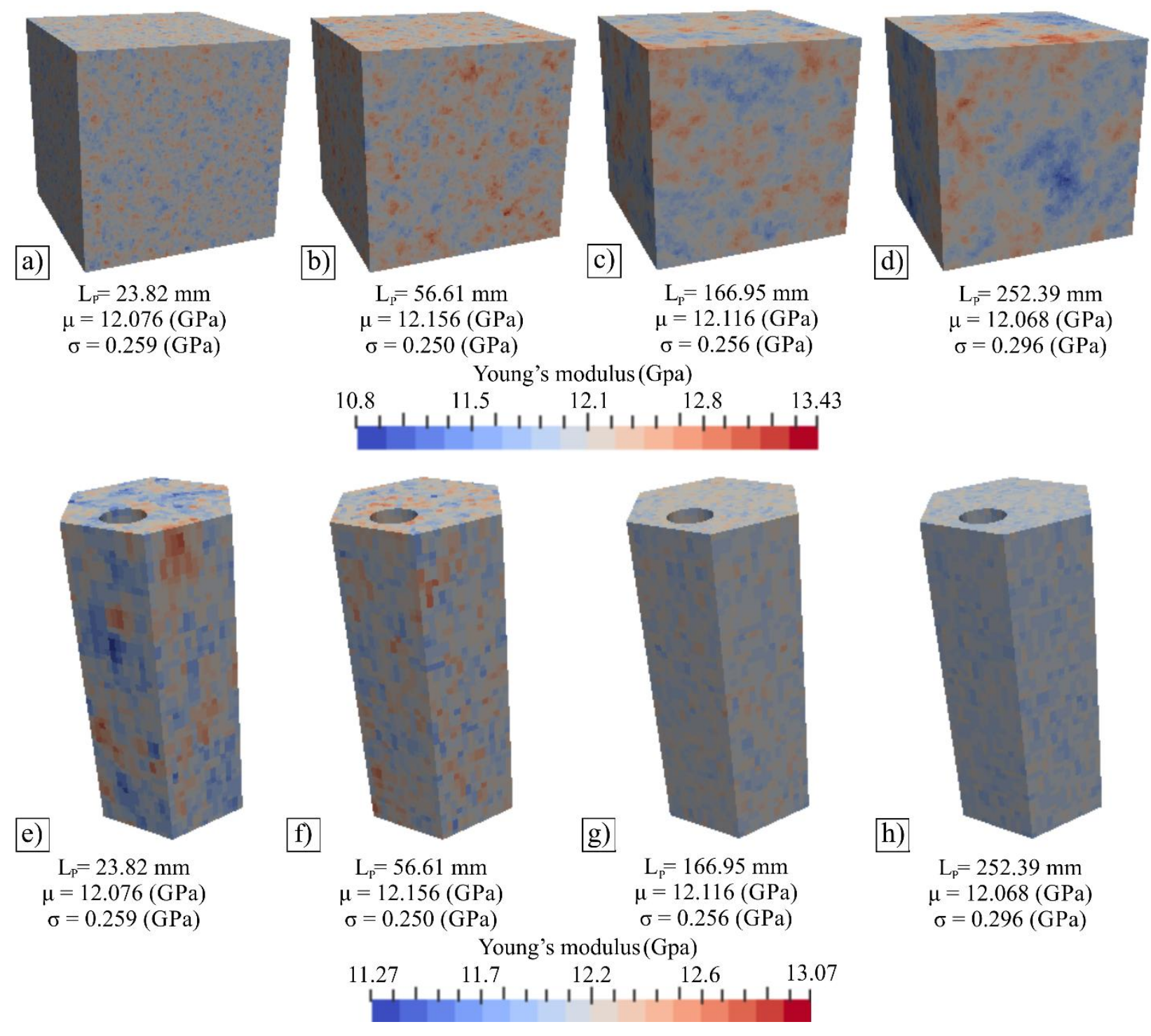

Figure 21. Random fields for Young's modulus data, the length of the sides of the cubes is 960 $\mathrm{mm}$ and show the effect of different correlation lengths on Young's modulus values. a) Random field - cube - Region 1, b) Random field - cube - Region 2, c) Random field - cube - Region 3, d) Random field - cube - Region 4, e) Random field - graphite brick - Region 1, f) Random field - graphite brick - Region 2, g) Random field - graphite brick - Region 3, h) Random field - graphite brick - Region 4 


\section{Discussion}

A methodology to extract and process material property data to calculate the correlation length and other parameters necessary to calibrate a random field for nuclear graphite components has been presented. The correlation length or range is an important factor that measures the likelihood of finding similar material property values within a certain distance. Descriptive statistics cannot fully describe the spatial changes of material properties through a medium even though the material has the same mean and standard deviation. This can be proved by comparing the random fields of Figure 11, wherein these random fields share the same mean and standard deviation but a very different spatial distribution of material property values.

One interesting finding of this research is that the spatial distributions of material properties represented by the range or correlation length were different in the Gilsocarbon and NBG-18 billet. Multiple correlation length values were found across the different regions of the Gilsocarbon billet, showing that a more pronounced spatial variability can be expected in this billet. One factor that may contribute to the different values of correlation length is extraction of samples around the edge of the billet. Density and Young's modulus values tend to be higher and more constant through the edge of the billet. This edge effect produced larger correlation lengths that might not be found at the interior of a Gilscoarbon billet. In contrast, NBG-18 samples were taken across multiple regions reducing the edge effect, producing similar correlation lengths in Regions 1 to Region 3. These low correlation length values mean that spatial variations of mechanical properties can be expected across a billet of NBG-18. An interesting consequence might be the occurrence of "odd" or "outlier" data point in Arrhenius plots for graphite NBG-18 oxidation by air, as reported independently by Jo Jo Lee [40], Hans-Kemens Hinssen [41] and by S H Chi [42]. Since the size of specimens in these studies was maximum $25 \mathrm{~mm}$, it is very possible the "odd" specimens were cut from isolated local domains (islands) of low density graphite. Some examples of this short-range correlation are the "islands" found in the random field of Figure 19 and Figure 21.

Perhaps another important factor to consider is the relationship between density and other material properties. As described in Section 4.2 the correlation lengths of Young's modulus and density follow similar trends. Further evidence of this can be found in the aforementioned research by Yoda and Fujisaki [39], where they showed that graphite specimens with low density 
tend to have lower values of CTE and Young's modulus. These relationships can be included in FEM models by assigning higher values of Young's modulus or CTE to elements with higher density.

Spatial correlation is often overlooked in the normal assessment of graphite billets and FEM studies of nuclear graphite. Spatial material variability is a factor that may be contributor on the generation of defects and stress concentrations through the lifetime of a graphite component. Furthermore, the understanding of heterogeneity of graphite components could greatly benefit from the analysis of spatial variations proposed in this study. The correlation length calculations can also be a valuable tool to differentiate the effect of the grain size and proportions of filler and binder on the mechanical properties of graphite. Possibly very different correlation lengths could be associated with the grain size and mixtures of binder and filler. This relationship can be possibly calculated from measuring the grain size and porosity content of polarized optical micrographs of large areas. Examples of these types of micrographs are given in Figure 22. ASTM D8075-16 [43] guidelines can help identify the filler particles found in these images. The average grain size obtained by this technique could be possibly correlated to the dynamic Young's modulus and corresponding correlation length of the original or similar specimens.

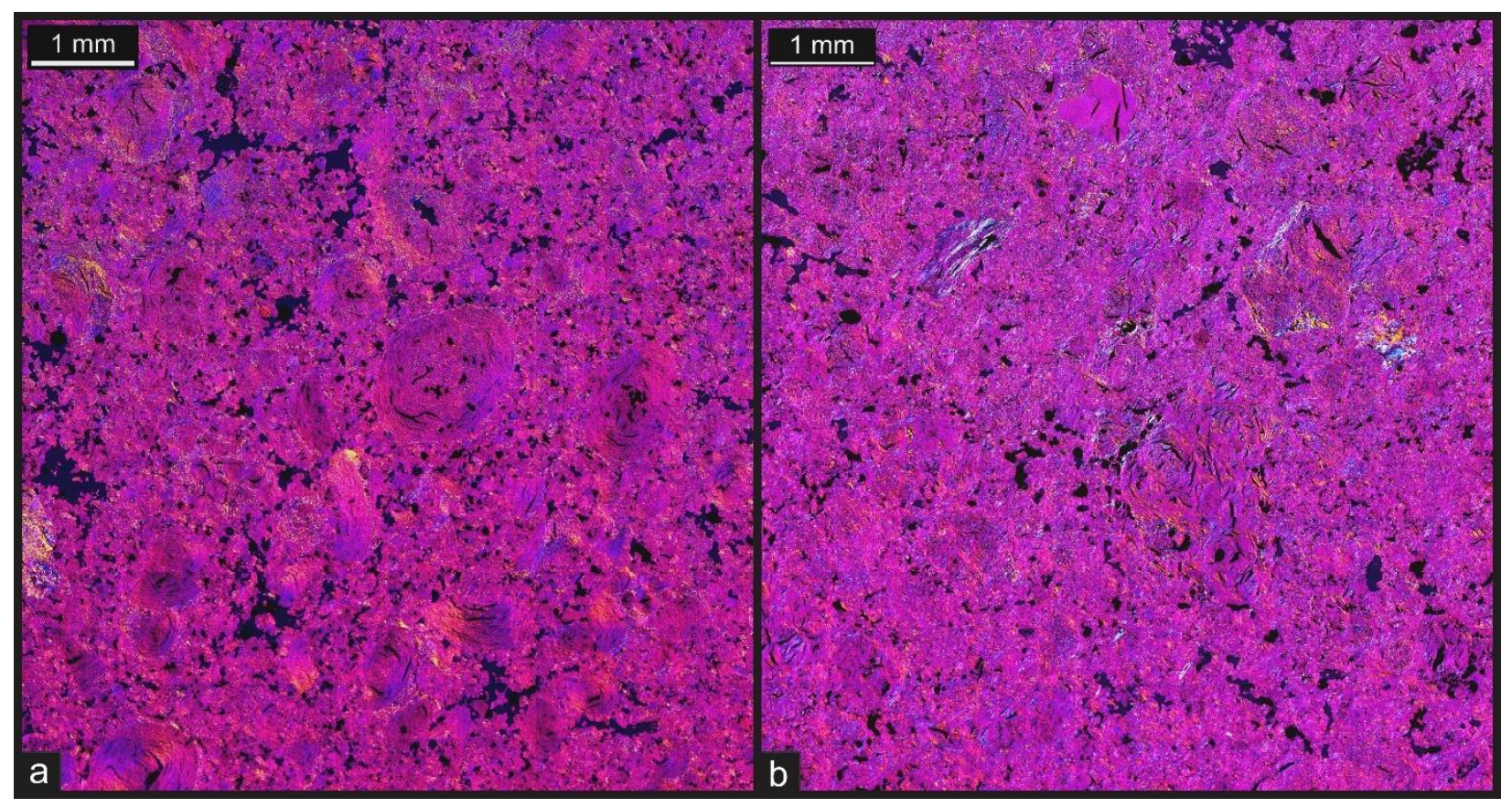


Figure 22. Polarized optical micrograph of the selected graphite grades a) Gilsocarbon, b) NBG18

Recent FEM studies have considered the spatial distribution of material properties in their studies $[10,44]$. However, these studies do not address a technique or procedure to determine how the spatial material variability would be determined. Historical $[18,19]$ and modern data $[24,45,46]$ would allow one to utilise the geostatistics tools used in this paper to obtain a new insight in the spatial variability of material mechanical properties.

Another advantage of including this methodology into the assessment of graphite billets is that it could reduce the number of specific component types that need to be inspected. Similar correlation length values at different regions of different billets would mean a more even distribution of material properties across graphite bricks and would ensure the quality of the material and manufacturing process.

\section{Summary and conclusions}

This study demonstrates the use of random field theory in the characterisation of spatial material variability as a new approach for modelling the heterogeneity of graphite components. The correlation length is a parameter that can help to quantify the degree of variability of density, Young's modulus or any another material property. Furthermore, FEM stress analysis can include random fields to measure the influence of spatial material variability under the reactor environment.

The main findings of this study research are described below:

1. Multiple correlation lengths values were found at the spines of the Gilsocarbon graphite billet. Practical correlation lengths ranged from 230.30 to $832.99 \mathrm{~mm}$ for density, and 204.63 to $1140.42 \mathrm{~mm}$ for Young's modulus data.

2. Very similar correlation length values were obtained for three of the regions of NBG-18 for both density and Young's modulus data. Only Region 4 presented higher values in both density and Young's modulus. This means that changes of material properties can be expected at different locations of this billet. 
3. Random fields can be used to reproduce the mean, standard deviation and correlation length in graphite components. These models can be included in FEM simulations to identify the influence of spatial material variability. The generation of random fields would also allow sensitivity studies to be performed on the statistical parameters (mean, standard deviation, probability distribution and correlation length) of different graphite grades.

4. The correlation length can be an important additional parameter to determine the degree of heterogeneity in a nuclear graphite component.

\section{Acknowledgements}

The authors would like to acknowledge Gyanender Singh for providing the geometry files of the prismatic graphite brick. Oak Ridge National Laboratory is managed by UT-Battelle, LLC under Contract No. DE-AC05-00OR22725 for the U.S. Department of Energy. This work was supported by the ORNL Postdoctoral Performance Development program.

\section{References}

[1] B.J. Marsden, G.N. Hall, 4.11 - Graphite in Gas-Cooled Reactors, in: R.J.M. Konings (Ed.), Comprehensive Nuclear Materials, Elsevier, Oxford, 2012, pp. 325-390.

[2] K. McNally, G. Hall, E. Tan, B.J. Marsden, N. Warren, Calibration of dimensional change in finite element models using AGR moderator brick measurements, Journal of Nuclear Materials 451(1-3) (2014) 179-188.

[3] D.K.L. Tsang, B.J. Marsden, The development of a stress analysis code for nuclear graphite components in gas-cooled reactors, Journal of Nuclear Materials 350(3) (2006) 208-220.

[4] D.K.L. Tsang, B.J. Marsden, Effects of dimensional change strain in nuclear graphite component stress analysis, Nuclear Engineering and Design 237(9) (2007) 897-904.

[5] T.-T.-G. Vo, P. Martinuzzi, V.-X. Tran, N. McLachlan, A. Steer, Modelling 3D crack propagation in ageing graphite bricks of Advanced Gas-Cooled Reactor Power Plant, 11th National Conference on Nuclear Science and Technology Agenda and Abstracts, Viet Nam, 2015 , p. 213.

[6] M. Wadsworth, S.T. Kyaw, W. Sun, Finite element modelling of the effect of temperature and neutron dose on the fracture behaviour of nuclear reactor graphite bricks, Nuclear Engineering and Design 280 (2014) 1-7.

[7] Z. Zou, S.L. Fok, B.J. Marsden, S.O. Oyadiji, Numerical simulation of strength test on graphite moderator bricks using a continuum damage mechanics model, Engineering Fracture Mechanics 73(3) (2006) 318-330.

[8] Z. Zou, S.L. Fok, S.O. Oyadiji, B.J. Marsden, Failure predictions for nuclear graphite using a continuum damage mechanics model, Journal of Nuclear Materials 324(2-3) (2004) 116-124.

[9] M. Srinivasan, On estimating the fracture probability of nuclear graphite components, Journal of Nuclear Materials 381(1-2) (2008) 185-198. 
[10] J.D. Arregui-Mena, L. Margetts, D.V. Griffiths, L. Lever, G. Hall, P.M. Mummery, Spatial variability in the coefficient of thermal expansion induces pre-service stresses in computer models of virgin Gilsocarbon bricks, Journal of Nuclear Materials 465 (2015) 793-804.

[11] M. Bansal, I.V. Singh, B.K. Mishra, K. Sharma, I.A. Khan, A stochastic XFEM model for the tensile strength prediction of heterogeneous graphite based on microstructural observations, Journal of Nuclear Materials 487 (2017) 143-157.

[12] L. Lin, H. Li, A.S.L. Fok, M. Joyce, J. Marrow, Characterization of heterogeneity and nonlinearity in material properties of nuclear graphite using an inverse method, Journal of Nuclear Materials 381(1) (2008) 158-164.

[13] C.N. Morrison, A.P. Jivkov, Y. Vertyagina, T.J. Marrow, Multi-scale modelling of nuclear graphite tensile strength using the site-bond lattice model, Carbon 100 (2016) 273-282.

[14] J. Kane, C. Karthik, D.P. Butt, W.E. Windes, R. Ubic, Microstructural characterization and pore structure analysis of nuclear graphite, Journal of Nuclear Materials 415(2) (2011) 189-197.

[15] J. Sumita, T. Shibata, I. Fujita, E. Kunimoto, M. Yamaji, M. Eto, T. Konishi, K. Sawa, Development of evaluation method with X-ray tomography for material property of IG-430 graphite for VHTR/HTGR, Nuclear Engineering and Design 271 (2014) 314-317.

[16] J.D. Arregui-Mena, P.D. Edmondson, A.A. Campbell, Y. Katoh, Site specific, highresolution characterisation of porosity in graphite using FIB-SEM tomography, Journal of Nuclear Materials (2018).

[17] D.J. Johns, Thermal stress analyses / by D.J. Johns, Pergamon1965.

[18] S.D. Preston, The statistical variation present in the material properties of Dungeness, Hartlepool, Heysham I and Heysham II/ Torness CAGR moderator graphites United Kingdom Atomic Energy Authority Northern Division, 1986.

[19] S.D. Preston, Variation of material properties within a single brick of the Heysham 2/Torness moderator graphite, United Kingdom Atomic Energy Authority Northern Division, 1988.

[20] S.D. Preston, The effect of material property variations on the failure probability of an AGR moderator brick subject to irradiation induced self stress, Department of Pure and Applied Physics, Univeristy of Salford, 1989.

[21] N. Nemeth, A. Walker, E. Baker, P. Murthy, R. Bratton, Large-scale Weibull analysis of H451 nuclear-grade graphite rupture strength, Carbon 58 (2013) 208-225.

[22] R. Price, Statistical study of the strength of near-isotropic graphite, GA-A13955 and UC-77, General Atomic Project 3224, 1976.

[23] T. Arai, S. Sato, T. Oku, H. Schiffers, W. Delle, Assessment of Heterogeneity and Anisotropy of IG-110 Graphite for Nuclear Components, Journal of Nuclear Science and Technology 28(8) (1991) 713-720.

[24] M. Carroll, J. Lord, D. Rohrbaugh, Baseline Graphite Characterization: First Billet, Idaho National Laboratory, United States, 2010.

[25] B.E. Mironov, A.V.K. Westwood, A.J. Scott, R. Brydson, A.N. Jones, Structure of different grades of nuclear graphite, Journal of Physics: Conference Series 371(1) (2012) 012017.

[26] J.D. Arregui-Mena, W. Bodel, R.N. Worth, L. Margetts, P.M. Mummery, Spatial variability in the mechanical properties of Gilsocarbon, Carbon 110(Supplement C) (2016) 497-517.

[27] L.B. Robert, B. Tim, AGC-1 Experiment and Final Preliminary Design Report, United States, 2006, p. 275.

[28] W. Windes, Data Report on Post-Irradiation Dimensional Change of AGC-1 Samples, ; Idaho National Laboratory (INL), 2012, p. Medium: ED. 
[29] W.E. Windes, W.D. Swank, D.T. Rohrbaugh, D.L. Cottle, AGC-2 Specimen Post Irradiation Data Package Report, ; Idaho National Laboratory (INL), Idaho Falls, ID (United States), 2015, p. Medium: ED; Size: 167 p.

[30] ASTM, ASTM C559-90(2010), Standard Test Method for Bulk Density by Physical Measurements of Manufactured Carbon and Graphite Article, West Conshohocken, PA, 2010.

[31] ASTM, ASTM D7219-08(2014), Standard Specification for Isotropic and Near-isotropic Nuclear Graphites, West Conshohocken, PA, 2014.

[32] J.D. Arregui-Mena, W. Bodel, R.N. Worth, L. Margetts, P.M. Mummery, Spatial variability in the mechanical properties of Gilsocarbon, Carbon (2016).

[33] M.A. Oliver, R. Webster, A tutorial guide to geostatistics: Computing and modelling variograms and kriging, CATENA 113 (2014) 56-69.

[34] M. Trauth, MATLAB® Recipes for Earth Sciences, Fourth ed., Springer-Verlag Berlin Heidelberg2015.

[35] H. Wackernagel, Multivariate geostatistics : an introduction with applications, 2nd, completely rev. ed., Springer, Berlin ; New York, 1998.

[36] W. Schwanghart, variogramfit, MATLAB Central File Exchange, Retrieved Sep 22, 2016, 2010.

[37] G.A. Fenton, D.V. Griffiths, Random Field Generation and the Local Average Subdivision Method, in: D.V. Griffiths, G.A. Fenton (Eds.), Probabilistic Methods in Geotechnical Engineering, Springer Vienna, Vienna, 2007, pp. 201-223.

[38] S. Yoda, K. Fujisaki, An approximate relation between Young's modulus and thermal expansion coefficient for nuclear-grade graphite, Journal of Nuclear Materials 113(2-3) (1983) 263-267.

[39] S. Yoda, K. Fujisaki, An approximate relation between Young's modulus and thermal expansion coefficient for nuclear-grade graphite, Journal of Nuclear Materials 113(2/3) (1983) 263-267.

[40] J.J. Lee, T.K. Ghosh, S.K. Loyalka, Comparison of NBG-18, NBG-17, IG-110 and IG-11 oxidation kinetics in air, Journal of Nuclear Materials 500 (2018) 64-71.

[41] H.-K. Hinseen, K. Kühn, R. Moormann, M. Fechter, M. Mitchell, Oxidation Experiments and theoretical examinations on graphite materials relevant for the PBMR, 3rd International Topical Meeting on High Temperature Reactor Technology, Johannesburg, South Africa, 2006.

[42] S.-H. Chi, E.-S. Kim, M.-H. Kim, Oxidation Behaviors of NBG-18 and NBG-25 Nuclear Graphite Grades INGSM-18, Baltimore, Maryland, USA, 2017.

[43] ASTM, ASTM D8075-16, Standard Guide for Categorization of Microstructural and Microtextural Features Observed in Optical Micrographs of Graphite, ASTM International, West Conshohocken, PA, 2016.

[44] P. Martinuzzi, L. Pellet, D. Geoffroy, Modelling crack propagation in irradiated graphite, in: P.E.J.F.a.A.J. Wickham (Ed.), The 4th EDF Energy Nuclear Graphite Symposium. Engineering Challenges Associated with the Life of Graphite Reactor Cores, EMAS, UK, 2014.

[45] P. Béghein, G. Berlioux, B.d. Mesnildot, F. Hiltmann, M. Melin, NBG-17 - An improved graphite grade for HTRs and VHTRs, Nuclear Engineering and Design 251 (2012) 146-149.

[46] A.A. Campbell, Y. Katoh, M.A. Snead, K. Takizawa, Property changes of G347A graphite due to neutron irradiation, Carbon 109 (2016) 860-873. 